\title{
Induction of LYVE-1/stabilin-2-positive liver sinusoidal endothelial-like cells from embryoid bodies by modulation of adrenomedullin-RAMP2 signaling
}

Takuma Arai ${ }^{\text {a,c }}$, Takayuki Sakurai ${ }^{\text {a }}$, Akiko Kamiyoshi ${ }^{\text {a }}$, Yuka Ichikawa-Shindo ${ }^{\text {a }}$, Nobuyoshi Iinuma ${ }^{a, c}$, Yasuhiro Iesato ${ }^{\text {a,b }}$, Teruhide Koyama ${ }^{a}$, Takahiro Yoshizawa ${ }^{\text {a }}$, Ryuichi Uetake ${ }^{a}$, Akihiro Yamauchi ${ }^{\text {a }}$, Lei Yang ${ }^{\mathrm{a}}$, Hisaka Kawate ${ }^{\mathrm{a}}$, Shinichiro Ogawa ${ }^{\mathrm{c}}$, Akira Kobayashi ${ }^{c}$,Shinichi Miyagawa ${ }^{c}$, Takayuki Shindo ${ }^{a}$

${ }^{a}$ Department of Organ Regeneration, Shinshu University Graduate School of Medicine, Japan

${ }^{\mathrm{b}}$ Department of Ophthalmology, Shinshu University Graduate School of Medicine, Japan

${ }^{\mathrm{c}}$ Department of Surgery, Shinshu University Graduate School of Medicine, Japan

Running Head: Induction of LYVE-1/stabilin-2-positive endothelial cells

\section{Address for correspondence}

Takayuki Shindo, MD, PhD

Department of Organ Regeneration,

Shinshu University Graduate School of Medicine

Asahi 3-1-1, Matsumoto, Nagano, 390-8621, Japan

Tel: $+81-263-37-3192$

Fax: +81-263-37-3437

Email: tshindo@shinshu-u.ac.jp 


\begin{abstract}
Embryonic stem cells (ESCs) are a useful source for various cell lineages. So
\end{abstract} far, however, progress toward reconstitution of mature liver morphology and function has been limited. We have shown that knockout mice deficient in adrenomedullin (AM), a multifunctional endogenous peptide, or its receptor-activity modifying protein (RAMP2) die in utero due to poor vascular development and hemorrhage within the liver. In this study, using embryoid bodies (EBs)-culture system, we successfully induced liver sinusoidal endothelial-like cells by modulation of AM-RAMP2. In an EB differentiation system, we found that co-administration of AM and SB431542, an inhibitor of transforming growth factor $\beta$ (TGF $\beta$ ) receptor type 1 , markedly enhanced differentiation of lymphatic vessel endothelial hyaluronan receptor-1 (LYVE-1)/stabilin-2-positive endothelial cells. These cells showed robust endocytosis of acetylated low-density lipoprotein (Ac-LDL) and upregulated expression of liver sinusoidal endothelial cells (LSECs)-specific markers, including factor 8 (F8), Fc- $\gamma$ receptor $2 \mathrm{~b}$ (Fcgr2b), and mannose receptor $\mathrm{C}$ type 1 (Mrc1), and also possess fenestrae-like structure, a key morphological feature of LSECs. In RAMP2-null liver, by contrast, LYVE-1 was downregulated in LSECs, and the sinusoidal structure was disrupted. Our findings highlight the importance of AM-RAMP2 signaling for 
development of LSECs.

\section{Key words}

Adrenomedullin (AM)

Receptor activity-modifying protein (RAMP)

Lymphatic vessel endothelial hyaluronan receptor-1 (LYVE-1)

stabilin-2

Liver sinusoidal endothelial cells (LSEC)

Embryonic stem cells 
Abbreviations

ESCs; Embryonic stem cells

EBs; Embryoid bodies

Ac-LDL; Acetylated low-density lipoprotein

AM; Adrenomedullin

RAMP; Receptor activity-modifying protein

CRLR; Calcitonin receptor-like receptor

GPCR; G protein-coupled receptor

TGF- $\beta ; \quad$ Transforming growth factor $\beta$ (TGF $\beta$ )

LYVE-1; Lymphatic vessel endothelial hyaluronan receptor-1

LSEC; Liver sinusoidal endothelial cells

LECs; Lymphatic endothelial cells

VEGF-A; Vascular endothelial growth factor A

VEGFR; Vascular endothelial growth factor receptor

ALK1, 5; Activin receptor-like kinase 1, 5

F8; $\quad$ Factor 8

Fcgr $2 b ; \quad$ Fc- $\gamma$ receptor $2 b$

Mrc1; $\quad$ Mannose receptor C type 1 


\section{Introduction}

Liver regeneration has long been desired as an alternative to transplantation of the organ. But while the pluripotency of embryonic stem cells (ESCs) has been exploited to obtain a variety of cell lineages for medical and research applications, progress toward reconstitution of mature liver morphology and function has been limited. Matsumoto et al. showed that primitive endothelial cells localized in the septum transversum are crucial for induction of the initial liver bud and for subsequent liver development[19]. In addition, Ogawa et al. recently reported that the emergence of cardiomyocytes and expansion of an endothelial cell network derived from ESCs plays an important role in the proliferation of hepatocytes and in liver organogenesis[26]. This suggests that differentiation of endothelial cells and reconstitution of the vasculature are key elements necessary for regeneration of mature liver.

Liver sinusoidal endothelial cells (LSECs) have unique structural and functional characteristics, among which are fenestrae and robust endocytic activity[5, 30]. Otherwise these cells are characterized physiologically as highly specialized scavenger endothelial cells that express such scavenger receptors as the mannose receptor, the Fc- $\gamma$ receptor and stabilin-2[6, 24, 30]. The mechanism underlying the development of LSECs remains largely unknown, but several similarities between lymphatic endothelial 
cells (LECs) and LSECs have been noted. For example, both LECs and LSECs have minimal basement membranes and loose cell-cell junctions, and both express lymphatic vessel endothelial hyaluronan receptor-1 (LYVE-1)[17]. This suggests that differentiation of LECs and LSECs is regulated to some degree via the same signaling pathways. Consistent with that idea, recent reports have shown that inhibition of endogenous transforming growth factor $\beta$ (TGF $\beta$ ) signaling enhances lymphangiogenesis and differentiation of fetal sinusoidal endothelial cells[27, 34]. Adrenomedullin (AM) is a multifunctional polypeptide originally isolated from human pheochromocytoma[14]. A noteworthy feature of AM is the unique system controlling its signaling[16, 20, 22, 28]. The AM receptor is a 7-transmembrane domain G protein-coupled receptor (GPCR) named calcitonin receptor-like receptor (CRLR), which associates with an accessory protein, receptor activity-modifying protein (RAMP). Three RAMP subtypes (RAMP1, 2, 3) have been identified. By interacting with RAMP1, CRLR acquires a high affinity for calcitonin gene-related peptide (CGRP), whereas by interacting with either RAMP2 or RAMP3, CRLR acquires a high affinity for AM. Homozygous AM and RAMP2 knockout (AM-/-, RAMP2-/-) mice die midgestation, on embryonic day (E)13.5 and E14.5, respectively. These AM-/- and RAMP2-/- mice share highly conserved phenotypes that include 
generalized edema, as well as severe hemorrhagic changes within the liver and poor vascular formation[11, 29]. These phenotypes suggest that the AM-RAMP2 system is required for blood and lymphatic vessel function throughout embryogenesis, and that LSEC differentiation and sinusoidal morphogenesis may be regulated by the AM-RAMP2 system[4, 8, 11-13, 29].

The purpose of the present study is to generate LSECs using ESCs-derived embryoid bodies (EBs). To accomplish this, we focused on modulation of the AM-RAMP2 system. 


\section{Materials and methods}

\subsection{Culture of mouse embryonic stem cells}

E14-1 ES cells derived from 129/Ola were grown on mitomycin C-treated mouse embryonic fibroblast (MEF) feeder layers to maintain them in an undifferentiated state. The culture medium consisted of Dulbecco's modified Eagle's medium (DMEM) (Invitrogen, Carlsbad, CA) supplemented with 20\% fetal bovine serum (FBS) (MBL, Japan), $1 \mathrm{mM}$ sodium pyruvate (Invitrogen), $100 \mu \mathrm{M}$ nonessential amino acids (Invitrogen), $100 \mu \mathrm{M}$ 2-mercaptoethanol (Sigma-Aldrich, St. Louis, MO) and $10^{3} \mathrm{U} / \mathrm{ml}$ leukemia inhibitory factor (LIF) (Chemicon, CA). The medium was replaced daily. Prior to differentiation, ES cells were first passaged onto gelatin coated plates for 30 min to remove the MEFs, and then resuspended in Iscove's modified Dulbecco's medium (IMDM) (Invitrogen) containing 20\% FBS, 1mM sodium pyruvate, $100 \mu \mathrm{M}$ nonessential amino acids and $100 \mu \mathrm{M}$ 2-mercaptoethanol, without LIF, and then formed into a hanging drop at a concentration of 1,500 cells per $50 \mu 1$. The hanging drop was cultured for 4 days at $37^{\circ} \mathrm{C}$ under an atmosphere of $5 \% \mathrm{CO}_{2}$. The $15 \mathrm{EBs}$ formed in the drops were transferred onto a 35-mm dish coated with collagen type I (Iwaki, Japan), and were cultured in differentiation medium consisting of IMDM supplemented with $10 \%$ FBS, $1 \mathrm{mM}$ sodium pyruvate, $100 \mu \mathrm{M}$ nonessential amino acids and $100 \mu \mathrm{M}$ 
2-mercaptoethanol. The following growth factors or inhibitors were added to the differentiation medium as indicated: $20 \mathrm{ng} / \mathrm{ml}$ human vascular endothelial growth factor A (VEGF-A) (R\&D systems, Minneapolis, MN), $10^{-6}$ or $10^{-7} \mathrm{M}$ human recombinant AM (Shionogi, Japan), 10-6 M SB431542 (Sigma-Aldrich). SB431542 was dissolved in $100 \%$ dimethyl sulfoxide (DMSO) at a stock concentration of $10 \mathrm{mmol} / \mathrm{L}$. This stock was then diluted in medium, and $0.01 \%$ DMSO was used as the vehicle for SB431542 in each experiment. As a control, 0.01\% DMSO was also added to the AM group. The medium was replaced every other day.

2.2. Primary culture of fetal mouse liver cells

Fetal mouse livers at E14.5 were dissected free of adhering tissue under a stereomicroscope. The livers were then minced and dissociated using collagenase (Wako, Japan) in Hank's buffer (Invitrogen), after which the cells were seeded onto a collagen type I-coated dish and maintained in DMEM supplemented with 10\% FBS and $100 \mathrm{U} / \mathrm{ml}$ penicillin-100 $\mu \mathrm{g} / \mathrm{ml}$ streptomycin.

2.3. Primary culture of adult mouse liver sinusoidal endothelial cells Primary adult mouse LSECs were isolated using a two step collagenase perfusion 
and centrifugation protocol.[3] The isolated sinusoidal endothelial cells were cultured in EGM2-MV (Cambrex, Walkersville, MD) at $37^{\circ} \mathrm{C}$ under a $5 \% \mathrm{CO}_{2}$ atmosphere.

\subsection{Animals}

C57BL/6J mice were obtained from Charles River Laboratories Japan, Inc.

RAMP2-/- mice were originally generated in our group[11]. Because RAMP2-/- mice die in utero at E14.5, we analyzed embryonic liver from these and wild-type mice at E14.5. All animal experiments were conducted in accordance with the ethical guidelines of Shinshu University.

\subsection{RNA extraction and RT-PCR analysis}

Total RNA was extracted from the outgrowths of the EBs using Trizol Reagent (Invitrogen, Carlsbad, CA), after which it was treated with DNA-Free (Ambion, Austin, TX) to remove contaminating DNA, and 2- $\mu \mathrm{g}$ samples were subjected to reverse transcription using a High Capacity cDNA Reverse Transcription Kit (Applied Biosystems, Carlbad, CA). Semiquantitative reverse transcription polymerase chain reaction (RT-PCR) was then carried out using Ex Taq DNA polymerase (Takara, Japan). PCR primers are listed in Table 1. 
2.6. Quantitative real-time RT-PCR analysis

Quantitative real-time RT-PCR was carried out using an Applied Biosystems

7300 real time PCR System (Applied Biosystems) with SYBR green (Toyobo, Japan) or

Realtime PCR Master Mix (Toyobo) and TaqMan probe (MBL). Values were

normalized to mouse glyceraldehyde-3-phosphate dehydrogenase (GAPDH)

(Pre-Developed TaqMan ${ }^{\circledR}$ assay reagents, Applied Biosystems). PCR primers are

listed in Table 2.

\subsection{Immunohistochemical analysis}

Cultured EBs were fixed with 4\% paraformaldehyde/PBS for 20 min and then

permeabilized with $0.1 \%$ Triton $\mathrm{X}$ for $10 \mathrm{~min}$ at room temperature. Embryos and

livers were embedded in OCT compound (Sakura Finetek Japan Co., Tokyo, Japan),

after which $6-\mu \mathrm{m}$ sections were cut with a cryostat and mounted on glass slides. The sections were then fixed with $4 \%$ paraformaldehyde/PBS for $15 \mathrm{~min}$ and permeabilized with $0.1 \%$ Triton $\mathrm{X}$ for $10 \mathrm{~min}$ at room temperature. The fixed samples were incubated first for $30 \mathrm{~min}$ at room temperature in blocking buffer containing $4 \%$ goat serum (DAKO, Denmark) or 4\% donkey serum (Jackson Immunoresearch, West Grove, 
$\mathrm{PA}$ ), and then with a primary $\mathrm{Ab}$ overnight at $4{ }^{\circ} \mathrm{C}$ followed by a secondary $\mathrm{Ab}$ for $1 \mathrm{~h}$ at room temperature. The Abs used were rat anti-mouse CD31 (BD Pharmingen, San Jose, CA), rabbit anti-mouse LYVE-1 (RELIA Tech, Braunschweig, Germany), rat anti-mouse stabilin-2 (a kind gift from A. Miyajima, Tokyo University, Japan), goat anti-mouse albumin (Bethyl Laboratories, Montgomery, TX), Alexa 488-conjugated anti-rat or rabbit and Alexa 568-conjugated anti-rabbit or goat (Molecular Probes, Eugene, OR). For nuclear staining, the cells were incubated for $5 \mathrm{~min}$ at room temperature with 4',6-diamidino-2-phenylindole (DAPI).

2.8. Cellular uptake of scavenger ligands analysis

For cellular uptake of acetylated low-density lipoprotein (Ac-LDL), EBs were incubated with $10 \mu \mathrm{g} / \mathrm{ml}$ Alexa 488-conjugated Ac-LDL (molecular probes) at $37^{\circ} \mathrm{C}$ for $4 \mathrm{~h}$. After rinsing the dish three times with phosphate-buffered saline (PBS), the cellular uptake of Alexa488-conjugated Ac-LDL was examined using a fluorescence microscope (BZ-9000, Keyence, Japan).

\subsection{Scanning electron microscopy}

Cultured EBs and primary adult mouse LSECs were fixed with $2.0 \%$ 
glutaraldehyde. Samples were postfixed with $1.0 \%$ osmium tetroxide, freeze-dried with t-butyl alchol, sputter-coated with gold, and examined with JSM6510LV scanning electron microscope (JEOL, Tokyo, Japan).

\section{Results}

3.1. Gene expression in embryonic stem cells (ESCs)-derived embryoid bodies (EBs) during differentiation

We first used quantitative real-time RT-PCR to analyze the time course of brachyury, goosecoid and Flk-1 expression during EB formation in hanging drops (data not shown). Brachyury and goosecoid expression, which defines early mesoderm induction and development, was highest from day 3 to day 4 of EB formation and then declined. By contrast, expression of the early endothelial cell differentiation marker Flk-1 was first detected on day 3 and gradually increased until day 5 . We therefore estimated that early mesodermal differentiation in EBs gave way to endothelial cell differentiation on day 4, and so we transferred EBs onto collagen type I dishes for expansion and further induction of the endothelial cell lineage on that day. We mainly observed the outer regions of the cultured EBs on the matix (EB outgrowth) because in 
those areas vascular and cellular network formation was easily observed.

To assess expression of AM, TGF $\beta 1$ and their receptors during differentiation of EBs, we carried out a RT-PCR analysis using RNA extracted from undifferentiated ESCs and from ESC-derived EBs collected every 4 days from day 0 to day 20 (Fig. 1A).

RAMP2 and RAMP3 were already expressed in the undifferentiated ESCs (day 0). Type I TGFß receptor, activin receptor-like kinase (ALK) 5 was also dected in day 0. CRLR, VEGF and another type I TGFß receptor, ALK1 expression was first detected on day 4 and was sustained until day 20. RAMP3 expression was detected in the undifferentiated ESCs; it then disappeared by day 4 but reappeared on day 8, and its levels increased thereafter. By contrast, AM expression was not detected until day16, well after expression of its receptors.

3.2. AM enhances induction of CD31-positive endothelial cells in EBs during an early phase of differentiation

To assess the roles of VEGF and AM in vasculogenesis during early endothelial cell development, recombinant VEGF $(20 \mathrm{ng} / \mathrm{ml})$ and AM $\left(10^{-7} \mathrm{M}, 10^{-6} \mathrm{M}\right)$ were added to the cultures from day 4 to day 14 (Fig. 1B), and the number of CD31-positive cells in 
EB outgrowths was quantified by immunohistochemical analysis on day14 (Fig. 1C).

We found that the number of CD31-positive endothelial cells increased in the

VEGF-treated group. Moreover, adding AM in combination with VEGF significantly enhanced induction CD31-positive endothelial cells, as compared to VEGF alone (Fig. $1 \mathrm{C}, \mathrm{D})$.

We also analyzed lymphatic vessel endothelial hyaluronan receptor-1 (LYVE-1) expression during the early phase of EB development (days 4 to 14); however, no LYVE-1 positivity was detected in any group at this stage (data not shown). Therefore, to identify the stage at which LYVE-1-positive endothelial cells emerge, at a later phase (days 17 to 24) we double-immunostained cells in EB outgrowths for CD31 and LYVE-1 (Fig. 1E). A few CD31/LYVE-1 double positive endothelial cells were detected on days 17-20, but the numbers gradually increased up to day 24 . Interestingly, the emergence of LYVE-1-positive endothelial cells occurred at about the same time as the upregulation of AM expression (Fig. 1A).

3.3. AM and SB431542 enhance the induction of LYVE-1-positive endothelial cells during late phase differentiation 
sinusoidal endothelial cells (LSECs)-specific genes in the EB outgrowths during later phase differentiation. Stabilin-2 is a fasciclin-like hyaluronan receptor and specific LSEC marker used to distinguish LSECs from LECs. Inhibition of TGF $\beta$ receptor type 1, using its specific inhibitor, SB431542, reportedly promotes stabilin-2-positive endothelial cell differentiation in monolayer cultures of ESCs[25]. In the present study, we compared the effect of AM on LSEC differentiation with that of SB431542. Recombinant AM or SB431542 was added to later phase EBs (days 14 to 20) attached to collagen I-coated dishes (Fig. 2A). Quantitative RT-PCR analysis showed that LYVE-1 gene expression was significantly elevated about 2-fold, as compared to control, in both the AM- and SB431542-treated groups. Furthermore, when AM and SB431542 were added together, they acted synergistically to upregulate LYVE-1 about 8-fold (Fig. 2B).

AM and SB431542 each significantly upregulated stablin-2 expression and, as with LYVE-1, their co-administration synergistically enhanced stabilin-2 expression. Vascular endothelial growth factor receptor (VEGFR)3 and CD31, which are expressed in fetal LSECs[24], were also upregulated by AM and SB431542. By contrast, expression of Prox-1 and podoplanin, LECs-specific markers, was unaffected. Thus 
AM and SB431542 promote cell differentiation that is much more toward LSECs than LECs.

Immunohistochemical detection of CD31 and LYVE-1 in day 20 EB outgrowths revealed that the numbers of CD31/LYVE-1 double-positive endothelial cells were significantly increased by treatment with AM or SB431542 (Fig. 2C, D). And consistent with the quantitative RT-PCR results, AM and SB431542 acted synergistically to increase numbers of LYVE-1-positive endothelial cells (Fig. 2D). The proportion of LYVE-1-positive cells among the CD31-positive cells was nearly 70\%, whereas no LYVE-1-positive cells were found among the CD31-negative cells.

\author{
3.4. AM- and SB431542-induced, EB-derived, LYVE-1-positive endothelial cells \\ possess the characteristics of LSECs
}

To characterize the phenotype of EB-derived, LYVE-1-positive endothelial cells treated with AM and SB431542 in more detail, we initially carried out an immunohistochemical analysis in EBs treated with vehicle or AM+SB431542. Co-administration of AM and SB431542 promoted the appearance of LYVE-1 and stabilin-2 double-positive cells compared with control (Fig. 3A). This double 
positivity of LSECs for LYVE-1 and stabilin-2 was also deteced in primary cultures of LSECs from adult mouse liver (lower panel of Fig. 3A). Higher magnification of the same condition well-demonstrated this double-positivity in AM-SB431542-treated group (lower panel of Fig. 3B).

We also assessed the expression of LSEC-specific markers known to be expressed in mature liver. Using quantitative RT-PCR, we determined that the LSEC markers, factor (F8), Fc- $\gamma$ receptor $2 \mathrm{~b}$ (Fcgr2b) and mannose receptor $\mathrm{C}$ type 1 (Mrc1), were all significantly upregulated by AM and SB431542 (Fig. 3C). To then evaluate the functional properties of EB-derived endothelial cells, we assessed endocytosis of fluorescently labeled (Alexa 488-conjugated) acetylated low-density lipoprotein (Ac-LDL). AM- and SB431542-treated cells showed higher existence of the fluorescent-positive cells than control, which means greater endocytotic activity (Fig. 3D). At 4 hrs, AM- and SB431542-treated cells exhibited significantly greater endocytotic activity than untreated cells (Fig. 3E). On day 24 of the culture, morphological features of EB-derived LYVE-1-positive endothelial cells were compared with primary-cultured adult LSECs in the higher magnification (Fig. 3F upper panel) and in scanning electron microscopy (Fig. 3F lower panel). AM- and 
SB431542-treated EB-derived LYVE-1-positive endothelial cells revealed the presence of fenestrae-like structure, which are the most prominent feature of mature LSECs.

\author{
3.5. The crucial role played by the AM-RAMP2 system during hepatic sinusoidal \\ development and morphogenesis in vivo
}

To study hepatic sinusoidal endothelial development and morphogenesis, we carried out an immunohistochemical analysis to detect CD31 and LYVE-1 in liver from E14.5-embryos and adults (Fig. 4A). We found that whereas fetal LSECs expressed CD31 and LYVE-1 equally (Fig. 4A upper panel), adult LSECs showed much stronger expression of LYVE-1 than the fetal cells and less expression of CD31 (Fig. 4A lower panel). In addition, the CD31-positive cells were limited to the larger vessels in the adult liver. LYVE-1-positive LSECs already showed capillary-like structures and ductal formation in the E14.5 liver.

Analysis of hepatic gene expression revealed that AM, CRLR and RAMP2 are expressed during mid-to-late gestation and in newborns, and that AM expression gradually increases during development until it peaks in newborns. On the other hand, TGF $\beta 1$ expression is downregulated after birth (Fig. 4B). 
We have demonstrated that RAMP2, one of the AM-receptor modulating proteins, is a crucial determinant of AM's vascular function during development. AM-/- and RAMP2-/- mice die at midgestation because of vascular abnormalities [11, 29]. Immunohistochemical analysis using anti-CD31 and anti-LYVE-1 antibodies in E14.5 wild-type and RAMP2-/- embryo liver revealed downregulation of LYVE-1 expression in the sinusoidal endothelial cells (Fig. 4C). Quantitative RT-PCR analysis also revealed significant downregulation of LYVE-1 in the RAMP2-/- liver (Fig. 4D). 


\section{Discussion}

The purpose of this study was to induce liver sinusoidal endothelial cells (LSECs)

differentiation for the reconstitution of liver morphogenesis.

LSECs have unique features not seen in other vascular endothelial cells that make them more similar to lymphatic endothelilal cells (LECs). For example, both LECs and LSECs have minimal basement membranes and loose cell-cell junctions, and both express lymphatic vessel endothelial hyaluronan receptor-1 (LYVE-1)[17, 24].

Moreover, both LECs and LSECs originate from veins or mesenchyme[2, 10, 33].

That said, these two cell types clearly differ in some ways. For example, stabilin-2, Fc $\gamma$ Rs, Mrc1 and F8 are expressed in LSECs but not LECs, whereas podoplanin and Prox-1 are expressed in LECs, but not LSECs. LSECs also exhibit greater endocytotic activity than other types of endothelial cells[24]. In our study, LYVE-1-positive endothelial cells in EBs treated with AM and SB431542 expressed stabilin-2, and some exhibited fenestrae-like structures. In addition, transcription of the LSEC markers F8, Fcgr2b and Mrc1 was significantly upregulated, and the cells exhibited more robust endocytotic activity. On the other hand, expression of the specific LEC markers Prox-1 and podoplanin was unaffected. EB-derived, LYVE-1-positive endothelial 
cells induced with AM and SB431542 thus appear to possess the characteristics of

LSECs.

Matsumoto et al. showed that primitive endothelial cells localized in the septum

transversum play a crucial role in the induction of the initial liver bud and in subsequent

liver development[19]. Recently, Ogawa et al. reported that the emergence of

cardiomyocytes and the expansion of the endothelial cell network derived from ESCs

stimulate the proliferation of hepatocytes and liver organogenesis[26]. In addition,

Fujimori et al. reported that VEGF increases proliferation of endothelial and

hepatocyte-like cells in EBs[9]. In our study, LYVE-1-positive endothelial cells

migrated to and made contact with albumin-positive cells in EB outgrowths, after which

expression of mature hepatocyte markers increased (data not shown). This suggests

that through the induction of LSECs we can promote mature hepatic morphogenesis,

and that LSECs could be a crucial therapeutic target for regeneration of the liver.

Consistent with that idea, it was recently shown that transplanted sinusoidal endothelial

cells can repopulate the liver endothelium and correct the phenotype of hemophilia A

mice $[7,15]$, and several reports have shown that endothelial progenitor cell

transplantation ameliorates acute liver injury and liver cirrhosis in rats[18, 23, 31, 32]. 
the induction of LSECs. From our observation of brachyury, goosecoid and Flk-1 expression, we estimated that by day 4 early mesoderm differentiation in EBs gave way to endothelial cell differentiation. In addition, expression of CRLR and RAMP2, which together form an AM receptor, also started on day 4. These observations prompted us to test the effect AM on VEGF-induced endothelial differentiation beginning on day 4. Our finding that AM dose-dependently enhanced induction of CD31-positive endothelial cells during the early differentiation phase (days 4-14) is consistent with earlier observations made using Flk-1-positive cells sorted from ESCs[35]. By contrast, LYVE-1-positive endothelial cells were not seen at this stage in any group. We therefore suggest that at this stage CD31-positive endothelial cells had not yet expressed differentiation factors for specific endothelial cellular lineages. Therefore, we next determined the stage at which LYVE-1-positive endothelial cells emerged in EB outgrowths. A few CD31/LYVE-1 double-positive cells were detected on days 17-20, and their numbers gradually increased on days 22-24. Interestingly, the emergence of LYVE-1-positive endothelial cells and the upregulation of AM occurred at about the same time (day17). From these observations, we estimated that days14-17 is a critical period during which CD31-endothelial cells in EB outgrowths begin to 
respond to differentiation factors for specific cellar lineages. We therefore applied differentiation stimuli from day 14 . SB431542, a TGF- $\beta$ receptor type 1 inhibitor, reportedly promotes CD31/LYVE-1/stabilin-2 positive endothelial cell differentiation in monolayer cultures of ESCs [25]. In the present study, we found that AM-treatment from day 14 to day 20 also promoted the appearance of CD31/LYVE-1/stabilin-2-positive endothelial cells. Moreover, when administered together, AM and SB431542 acted synergistically to promote differentiation of CD31/LYVE-1/stabilin-2-positive endothelial cells. This result suggests, in the differentiation of LSECs, AM and TGF $\beta$-signaling show reverse correlation; TGF $\beta$-TGF $\beta$ receptor system suppresses LSEC differentiation. On the other hand, AM-RAMP2 system promotes it. TGF $\beta 1$ and type I TGFß receptor (ALK1 and ALK5) were expressed in EBs and their expanded culture on the collagen dish. In addition, TGF $\beta 1$ was rather uniformly expressed in the liver of embryo, new born, and adult mice. In contrast, the AM expression level is temporally regulated and appears at relatively later stage during embryogenesis. Montuenga et al. showed that during rodent embryogenesis, the expression of TGF $\beta 1$ and AM is spatially and temporally regulated such that their expression patterns overlap at the same stage of development in several tissues and in the same cellular locations[21]. It has also been shown that there is less 
AM expression in tissues from embryonic TGF $\beta 1$-null mice than in tissues from

wild-type mice, but that AM expression increases during postnatal development, even in TGF $\beta 1$-null mice[1]. Taken together, critical balance between TGF $\beta$-TGF $\beta$ receptor system and AM-RAMP2 system during development may determine the differentiation direction of endothelial cells. By a microarray analysis of AM and SB431542 co-administration condition in EBs, we confirmed the upregulation of LYVE-1. In contrast, we cannot detect specific changes in other angiogenic factors (Supplemental Table 1-3). This may suggest that in the co-administration of AM and SB431542, LYVE-1 upregulation is a critical determinant of LSEC differentiation.

It also has been previously reported that AM/cAMP is a novel signaling pathway that leads to activation of Notch signaling in differentiating endothelial cells, and is required for induction of arterial endothelial cells from Flk-1-positive cells sorted from ESCs in a monolayer culture system[35]. Our results are at variance to this report, and we suggest that the inconsistency reflects the difference in the culture systems used in the two studies: monolayer vs. semispheroid cultures and sorted purified cells vs. EBs that include endodermal and ectodermal cell lineages. Cell-cell interactions and unknown factors from endodermal and/or ectodermal cells may affect the endothelial cells in our culture system. 
Analysis of gene expression in the embryonic liver revealed that AM, CRLR and RAMP2 are expressed throughout liver development. AM expression increased gradually during development and peaked in newborns. In E14.5 RAMP2-/- liver, LYVE-1 expression was downregulated in sinusoidal endothelial cells, and the capillary network and sinusoidal structure were disrupted. This finding, together with the observed morphology and functionality of the cells in our EB culture system, suggests the AM-RAMP2 system plays a critical role in the differentiation of LSECs and in sinusoidal morphogenesis. We suggest that these results could serve as the basis for development of techniques for the regeneration of liver, and could also be useful in a variety of other medical and research applications, including bioartificial liver systems and drug metabolism assays. 


\section{Acknowledgement}

E14-1 ES cells were kindly provided by Dr. Yoh-ichi Tagawa (Frontier Research

Center and Department of Biomolecular Engineering, Graduate School of Bioscience

and Biotechnology, Tokyo Institute of Technology, Japan). Anti-stabilin $2 \mathrm{Ab}$ was

kindly provided by Dr. Atsushi Miyajima (Laboratory of Cell Growth and

Differentiation, Institute of Molecular and Cellular Biosciences, The University of

Tokyo, Japan). This study was supported by Funding Program for Next Generation

World-Leading Researchers from Cabinet Office, Government of Japan, Research Grant

for Cardiovascular Disease from National Cardiovascular Center, Research Grant from

Mitsui Life Social Welfare Foundation, Takeda Science Foundation, Kanzawa Medical

Research Foundation, Public Trust Fund for the Promotion of Surgery, Suzuken

Memorial Foundation, and Japan Heart Foundation. 


\title{
Figure legends
}

\section{Fig. 1}

\begin{abstract}
(A) Semiquantitative RT-PCR analysis of gene expression in ESC-derived EBs. RNA was extracted from undifferentiated ESCs (day 0, D 0) and from EBs on the indicated day and analyzed for expression of VEGF, AM, CRLR, RAMP2, RAMP3, TGF $\beta 1$,
\end{abstract} ALK1, ALK5 and HPRT. EBs were seeded onto collagen type I-coated dishes on day 4 and cultured in the absence of growth factors. (B) Protocol for the treatment of early phase EBs for endothelial cell differentiation. The medium was supplemented with VEGF and AM from day 4 to day14. (C) Immunohistochemical detection of CD31 (green) in EB outgrowths on day14. Scale bar $=200 \mu \mathrm{m} . \quad$ (D) Quantitative analysis of CD31-positive areas of EB outgrowths on day 14. Analyzed were 8 selected microscope fields. Bars are means $\pm \mathrm{SE}, * ; \mathrm{p}<0.01, * * ; \mathrm{p}<0.001 . \quad$ (E) Double immunostaining of CD31 (green) and LYVE-1 (red) in EB outgrowths cultured in the absence of growth factors on the indicated day. A few CD31/LYVE-1 double-positive endothelial cells were detected on days 17-20, but the number was increased on days 22-24. Scale bar $=200 \mu \mathrm{m}$.

\section{Fig. 2}


(A) Protocol for the treatment of late phase EBs for specific endothelial cell differentiation. To analyze the effect of AM and the TGF $\beta$ inhibitor SB431542 on late phase endothelial cell development, the medium was supplemented with recombinant AM $\left(10^{-6} \mathrm{M}\right)$ and/or SB431542 $\left(10^{-6} \mathrm{M}\right)$ from day 14 to day 20 . (B) Quantitative RT-PCR analysis of CD31, LEC-specific genes (LYVE-1, Prox-1, podoplanin, VEGFR3) and LSEC-specific genes (LYVE-1, stabilin-2, VEGFR3) in the outgrowths of day 17 EBs treated with vehicle, SB431542, AM and AM+SB431542. mRNA levels was normalized to that of GAPDH mRNA. Bars are means $\pm \mathrm{SE}, \mathrm{n}=3$ (each sample includes $15 \mathrm{EBs}) ;{ }^{*} \mathrm{p}<0.05,{ }^{* *} \mathrm{p}<0.001,{ }^{* * *} \mathrm{p}<0.0001$ vs. control, $\dagger \mathrm{p}<0.05$, $\dagger \mathrm{p}<0.0001$ vs. SB431542+AM. (C) Immunohistochemical detection of CD31 (green) and LYVE-1 (red) in 20 day EB outgrowths. Scale bar $=200 \mu \mathrm{m}$. (D) Quantitative analysis of the CD31- and LYVE-1-positive areas in 20 day EB outgrowths in 8 selected microscope fields. Bars are means $\pm \mathrm{SE},{ }^{*} \mathrm{p}<0.05,{ }^{* *} \mathrm{p}<0.01,{ }^{* * *} \mathrm{p}<0.001$ vs. control, $\dagger \mathrm{p}<0.01$ vs. AM.

\section{Fig. 3}

Phenotypic characterization of EB-derived, LYVE-1-positive endothelial cells treated with AM+SB431542. (A) Immunohistochemical detection of stabilin-2 (green) and 
LYVE-1 (red) in day 20 EBs treated with vehicle, AM+SB431542 and in primary cultured adult LSECs. Scale bar $=100 \mu \mathrm{m}$. (B) In high power field. Scale bar $=$ $100 \mu \mathrm{m} . \quad$ (C) Quantitative RT-PCR analysis of LSEC-specific genes in the outgrowths of day17 EBs treated with vehicle or AM+SB431542. $\square$ Control, AM+SB431542. mRNA levels was normalized to that of GAPDH mRNA. Bars are means \pm SE, $n=3$ (each of the sample includes $15 \mathrm{EBs}) ;{ }^{*}<<0.05,{ }^{*} \mathrm{p}<0.01$. Endocytotic activity in cultured EB outgrowths treated with vehicle or AM+SB431542 was estimated based on cellular uptake of Alexa 488-conjugated Ac-LDL (green) for 4 hrs and 24 hrs exposure. Scale bar $=300 \mu \mathrm{m}$. (E) Quantitative analysis of Alexa488-positive areas that were exposed for 4hours estimated in 8 selected microscope fields. $\square$ Control, $\square \mathrm{AM}+\mathrm{SB} 431542 . \quad$ Bars are means $\pm \mathrm{SE} ; * * \mathrm{p}<0.01$ (F) Morphological analysis of EB-derived LYVE-1-positive endothelial cells treated with vehicle, AM and SB431542 on day 24 (left) and primary-cultured adult LSECs (right) using immunostaining of anti-LYVE-1 antibody (red), and using scanning electron microscopy. Scale bar $=50 \mu \mathrm{m}$ (upper panel), $1 \mu \mathrm{m}$ (lower panel).

\section{Fig. 4}

(A) Immunohistochemical detection of CD31 (green) and LYVE-1 (red) in E14.5 and 
adult liver. Scale bar $=100 \mu \mathrm{m} . \quad$ (B) AM, CRLR, RAMP2, RAMP3, TGF $\beta 1$ and HPRT gene expression in E12.5, E14.5, E18.5, neonatal and adult livers. HPRT was amplified to normalize for the amount of RNA used as starting material. (C) Immunohistochemical detection of CD31 (green) and LYVE-1 (red) in E14.5 wild-type and RAMP2-/-embryo liver. Scale bar $=100 \mu \mathrm{m}$. (D) Quantitative RT-PCR analysis of AM, CRLR, RAMP2, RAMP3, LYVE-1 and CD31 in E14.5 wild-type and RAMP2-/- embryo liver. $\square$ Wild, $\square$ RAMP2-/-. mRNA levels were normalized to that of GAPDH mRNA. Bars are means \pm SE, $n=4$ per group; ${ }^{*} \mathrm{p}<0.05$. 


\section{References}

[1] Bodegas E, Martinez A, Ozbun LL, Garayoa M, Letterio JJ, Montuenga LM, et

al. Depressed adrenomedullin in the embryonic transforming growth factor-beta1 null mouse becomes elevated postnatally. Int J Dev Biol 2004;48:67-70.

[2] Buttler K, Kreysing A, von Kaisenberg CS, Schweigerer L, Gale N, Papoutsi M, et al. Mesenchymal cells with leukocyte and lymphendothelial characteristics in murine embryos. Dev Dyn 2006;235:1554-62.

[3] Deleve LD. Dacarbazine toxicity in murine liver cells: a model of hepatic endothelial injury and glutathione defense. J Pharmacol Exp Ther 1994;268:1261-70.

[4] Dunworth WP, Caron KM. G protein-coupled receptors as potential drug targets for lymphangiogenesis and lymphatic vascular diseases. Arterioscler Thromb Vasc Biol 2009;29:650-6.

[5] Enomoto K, Nishikawa Y, Omori Y, Tokairin T, Yoshida M, Ohi N, et al. Cell biology and pathology of liver sinusoidal endothelial cells. Med Electron Microsc 2004;37:208-15.

[6] Falkowski M, Schledzewski K, Hansen B, Goerdt S. Expression of stabilin-2, a novel fasciclin-like hyaluronan receptor protein, in murine sinusoidal endothelia, avascular tissues, and at solid/liquid interfaces. Histochem Cell Biol 2003;120:361-9. 
[7] Follenzi A, Benten D, Novikoff P, Faulkner L, Raut S, Gupta S. Transplanted endothelial cells repopulate the liver endothelium and correct the phenotype of hemophilia A mice. J Clin Invest 2008;118:935-45.

[8] Fritz-Six KL, Dunworth WP, Li M, Caron KM. Adrenomedullin signaling is necessary for murine lymphatic vascular development. J Clin Invest 2008;118:40-50.

[9] Fujimori H, Asahina K, Shimizu-Saito K, Ikeda R, Tanaka Y, Teramoto K, et al. Vascular endothelial growth factor promotes proliferation and function of hepatocyte-like cells in embryoid bodies formed from mouse embryonic stem cells. J Hepatol 2008;48:962-73.

[10] Gouysse G, Couvelard A, Frachon S, Bouvier R, Nejjari M, Dauge MC, et al. Relationship between vascular development and vascular differentiation during liver organogenesis in humans. J Hepatol 2002;37:730-40.

[11] Ichikawa-Shindo Y, Sakurai T, Kamiyoshi A, Kawate H, Iinuma N, Yoshizawa T, et al. The GPCR modulator protein RAMP2 is essential for angiogenesis and vascular integrity. J Clin Invest 2008;118:29-39.

[12] Iimuro S, Shindo T, Moriyama N, Amaki T, Niu P, Takeda N, et al. Angiogenic effects of adrenomedullin in ischemia and tumor growth. Circ Res 2004;95:415-23. 
[13] Jin D, Harada K, Ohnishi S, Yamahara K, Kangawa K, Nagaya N.

Adrenomedullin induces lymphangiogenesis and ameliorates secondary lymphoedema.

Cardiovasc Res 2008;80:339-45.

[14] Kitamura K, Sakata J, Kangawa K, Kojima M, Matsuo H, Eto T. Cloning and characterization of cDNA encoding a precursor for human adrenomedullin. Biochem Biophys Res Commun 1993;194:720-5.

[15] Kumaran V, Benten D, Follenzi A, Joseph B, Sarkar R, Gupta S.

Transplantation of endothelial cells corrects the phenotype in hemophilia A mice. $\mathbf{J}$ Thromb Haemost 2005;3:2022-31.

[16] Kuwasako K, Cao YN, Nagoshi Y, Kitamura K, Eto T. Adrenomedullin receptors: pharmacological features and possible pathophysiological roles. Peptides 2004;25:2003-12.

[17] Lalor PF, Lai WK, Curbishley SM, Shetty S, Adams DH. Human hepatic sinusoidal endothelial cells can be distinguished by expression of phenotypic markers related to their specialised functions in vivo. World J Gastroenterol 2006;12:5429-39. [18] Liu F, Liu ZD, Wu N, Cong X, Fei R, Chen HS, et al. Transplanted endothelial progenitor cells ameliorate carbon tetrachloride-induced liver cirrhosis in rats. Liver Transpl 2009;15:1092-100. 
[19] Matsumoto K, Yoshitomi H, Rossant J, Zaret KS. Liver organogenesis promoted by endothelial cells prior to vascular function. Science 2001;294:559-63.

[20] McLatchie LM, Fraser NJ, Main MJ, Wise A, Brown J, Thompson N, et al. RAMPs regulate the transport and ligand specificity of the calcitonin-receptor-like receptor. Nature 1998;393:333-9.

[21] Montuenga LM, Mariano JM, Prentice MA, Cuttitta F, Jakowlew SB.

Coordinate expression of transforming growth factor-beta1 and adrenomedullin in rodent embryogenesis. Endocrinology 1998;139:3946-57.

[22] Morfis M, Christopoulos A, Sexton PM. RAMPs: 5 years on, where to now? Trends Pharmacol Sci 2003;24:596-601.

[23] Nakamura T, Torimura T, Sakamoto M, Hashimoto O, Taniguchi E, Inoue K, et al. Significance and therapeutic potential of endothelial progenitor cell transplantation in a cirrhotic liver rat model. Gastroenterology 2007;133:91-107 e1.

[24] Nonaka H, Tanaka M, Suzuki K, Miyajima A. Development of murine hepatic sinusoidal endothelial cells characterized by the expression of hyaluronan receptors. Dev Dyn 2007;236:2258-67.

[25] Nonaka H, Watabe T, Saito S, Miyazono K, Miyajima A. Development of stabilin2+ endothelial cells from mouse embryonic stem cells by inhibition of 
TGFbeta/activin signaling. Biochem Biophys Res Commun 2008;375:256-60.

[26] Ogawa S, Tagawa Y, Kamiyoshi A, Suzuki A, Nakayama J, Hashikura Y, et al. Crucial roles of mesodermal cell lineages in a murine embryonic stem cell-derived in vitro liver organogenesis system. Stem Cells 2005;23:903-13.

[27] Oka M, Iwata C, Suzuki HI, Kiyono K, Morishita Y, Watabe T, et al. Inhibition of endogenous TGF-beta signaling enhances lymphangiogenesis. Blood 2008;111:4571-9.

[28] Parameswaran N, Spielman WS. RAMPs: The past, present and future. Trends Biochem Sci 2006;31:631-8.

[29] Shindo T, Kurihara Y, Nishimatsu H, Moriyama N, Kakoki M, Wang Y, et al. Vascular abnormalities and elevated blood pressure in mice lacking adrenomedullin gene. Circulation 2001;104:1964-71.

[30] Smedsrod B, Pertoft H, Gustafson S, Laurent TC. Scavenger functions of the liver endothelial cell. Biochem J 1990;266:313-27.

[31] Taniguchi E, Kin M, Torimura T, Nakamura T, Kumemura H, Hanada S, et al. Endothelial progenitor cell transplantation improves the survival following liver injury in mice. Gastroenterology 2006;130:521-31.

[32] Ueno T, Nakamura T, Torimura T, Sata M. Angiogenic cell therapy for hepatic 
fibrosis. Med Mol Morphol 2006;39:16-21.

[33] Wigle JT, Harvey N, Detmar M, Lagutina I, Grosveld G, Gunn MD, et al. An essential role for Prox1 in the induction of the lymphatic endothelial cell phenotype.

Embo J 2002;21:1505-13.

[34] Yoshida M, Nishikawa Y, Omori Y, Yoshioka T, Tokairin T, McCourt P, et al. Involvement of signaling of VEGF and TGF-beta in differentiation of sinusoidal endothelial cells during culture of fetal rat liver cells. Cell Tissue Res 2007;329:273-82. [35] Yurugi-Kobayashi T, Itoh H, Schroeder T, Nakano A, Narazaki G, Kita F, et al. Adrenomedullin/cyclic AMP pathway induces Notch activation and differentiation of arterial endothelial cells from vascular progenitors. Arterioscler Thromb Vasc Biol 2006;26:1977-84. 
A.

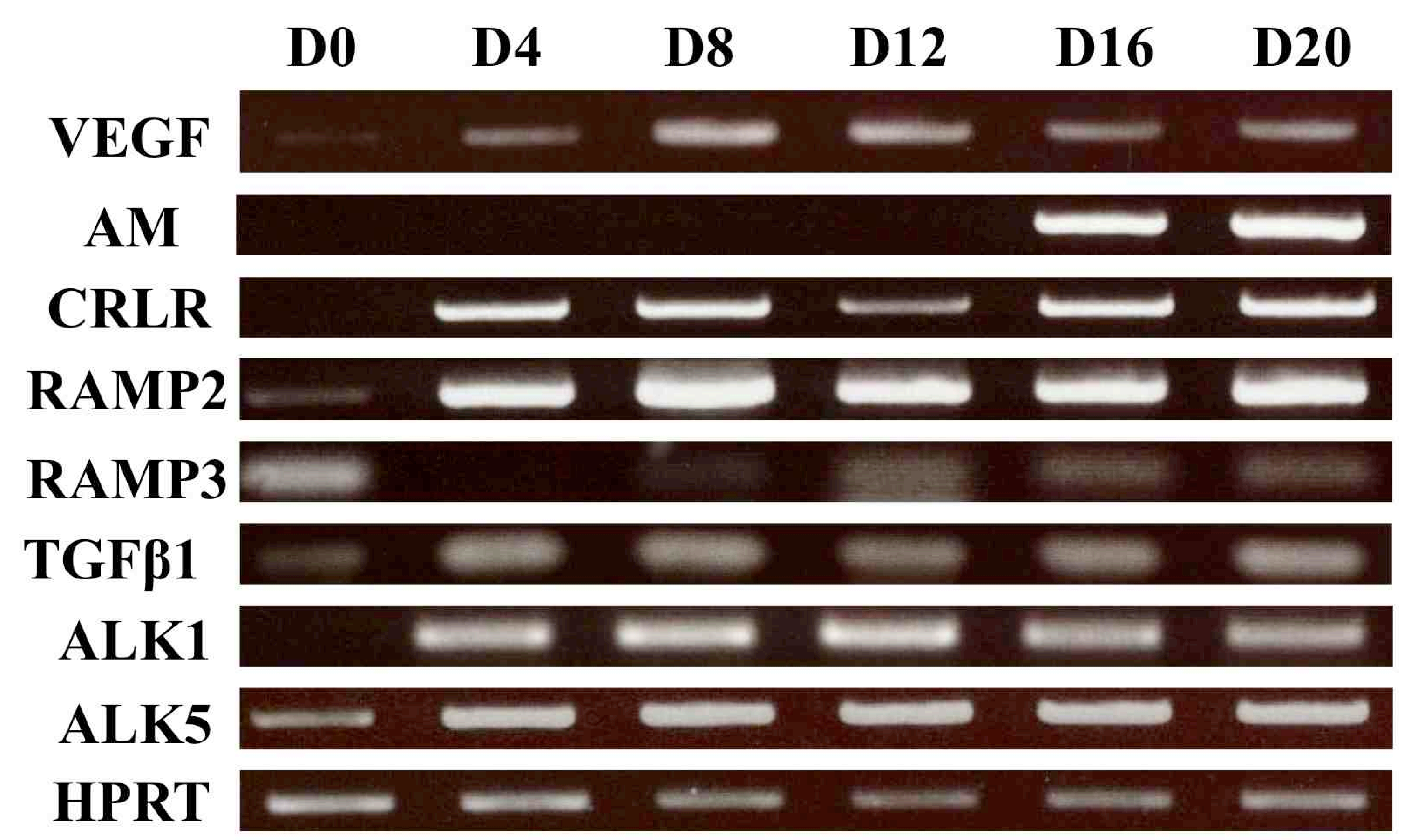

Fig 1. 
B.

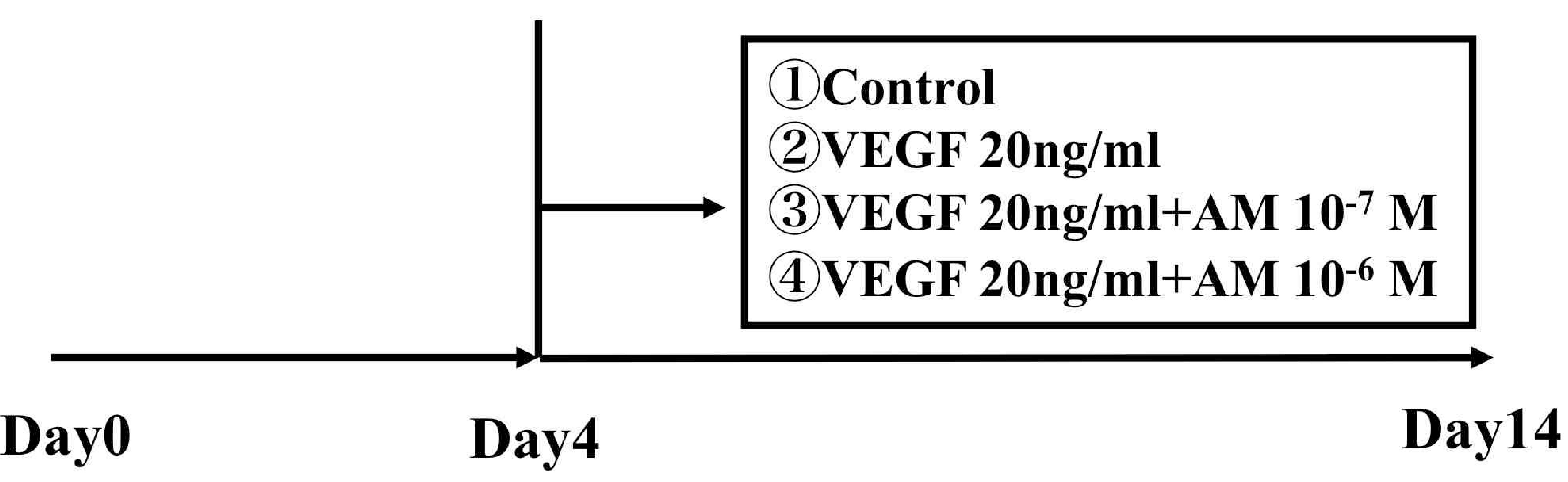




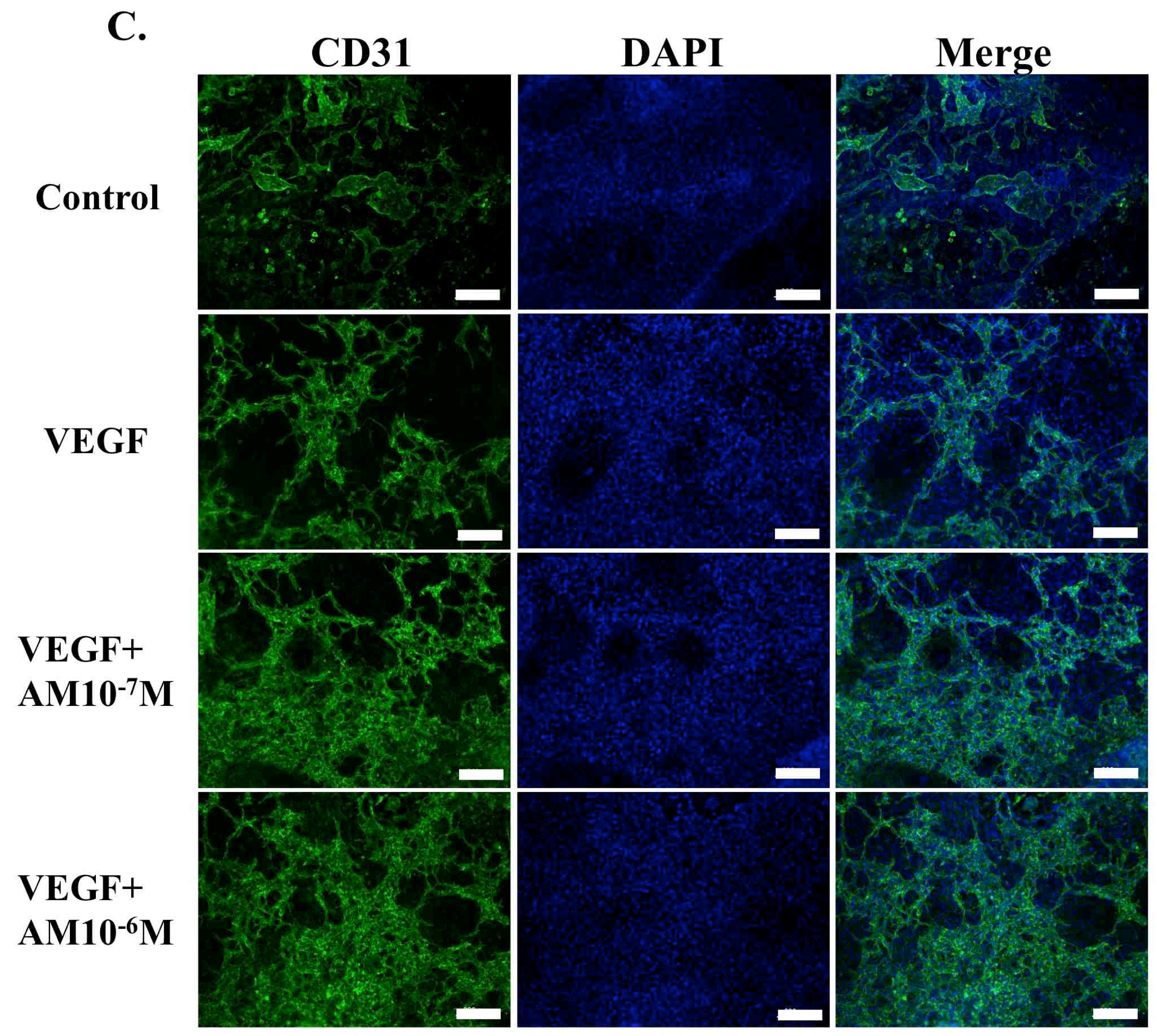

Fig 1. 
D.

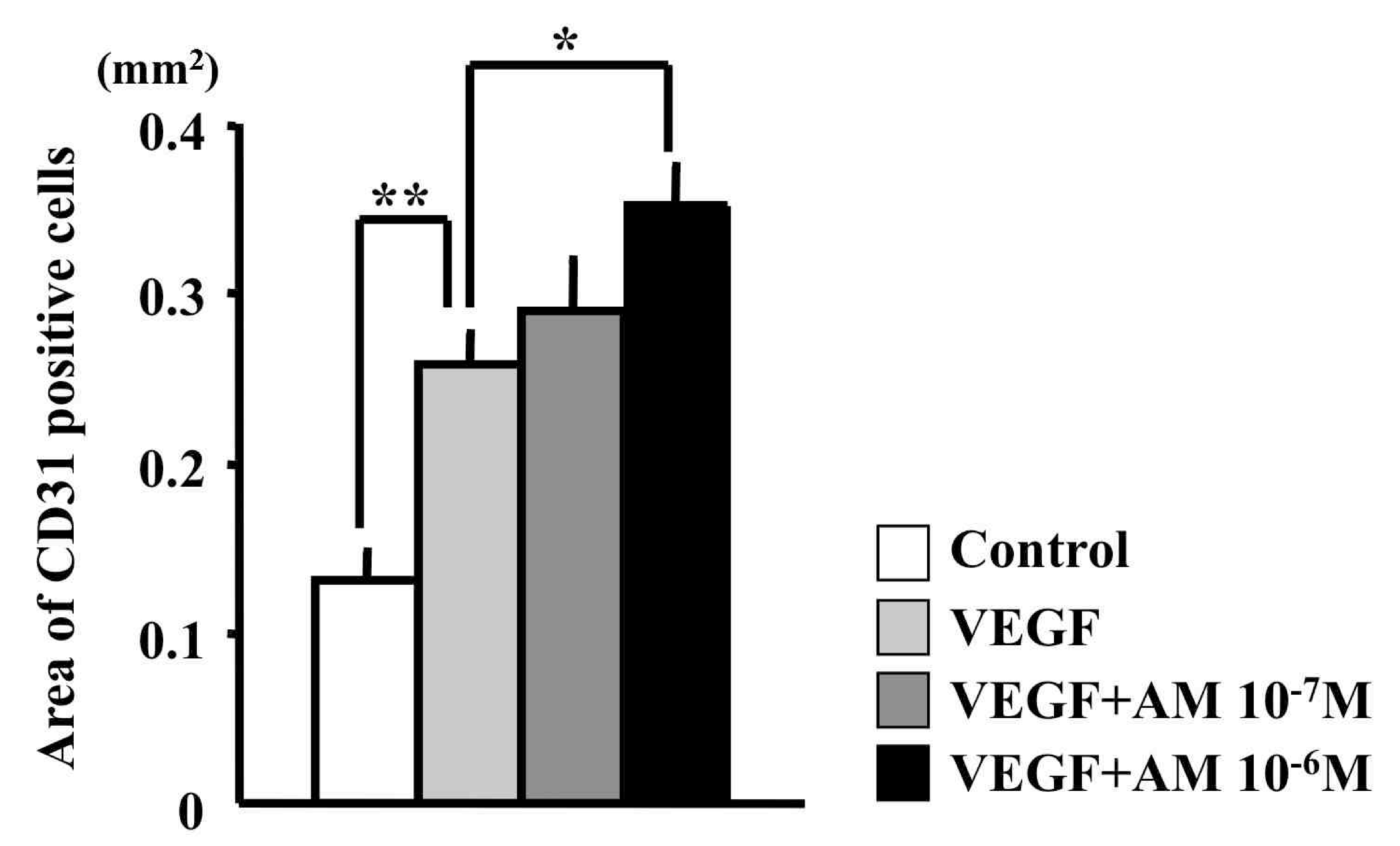

Fig 1. 


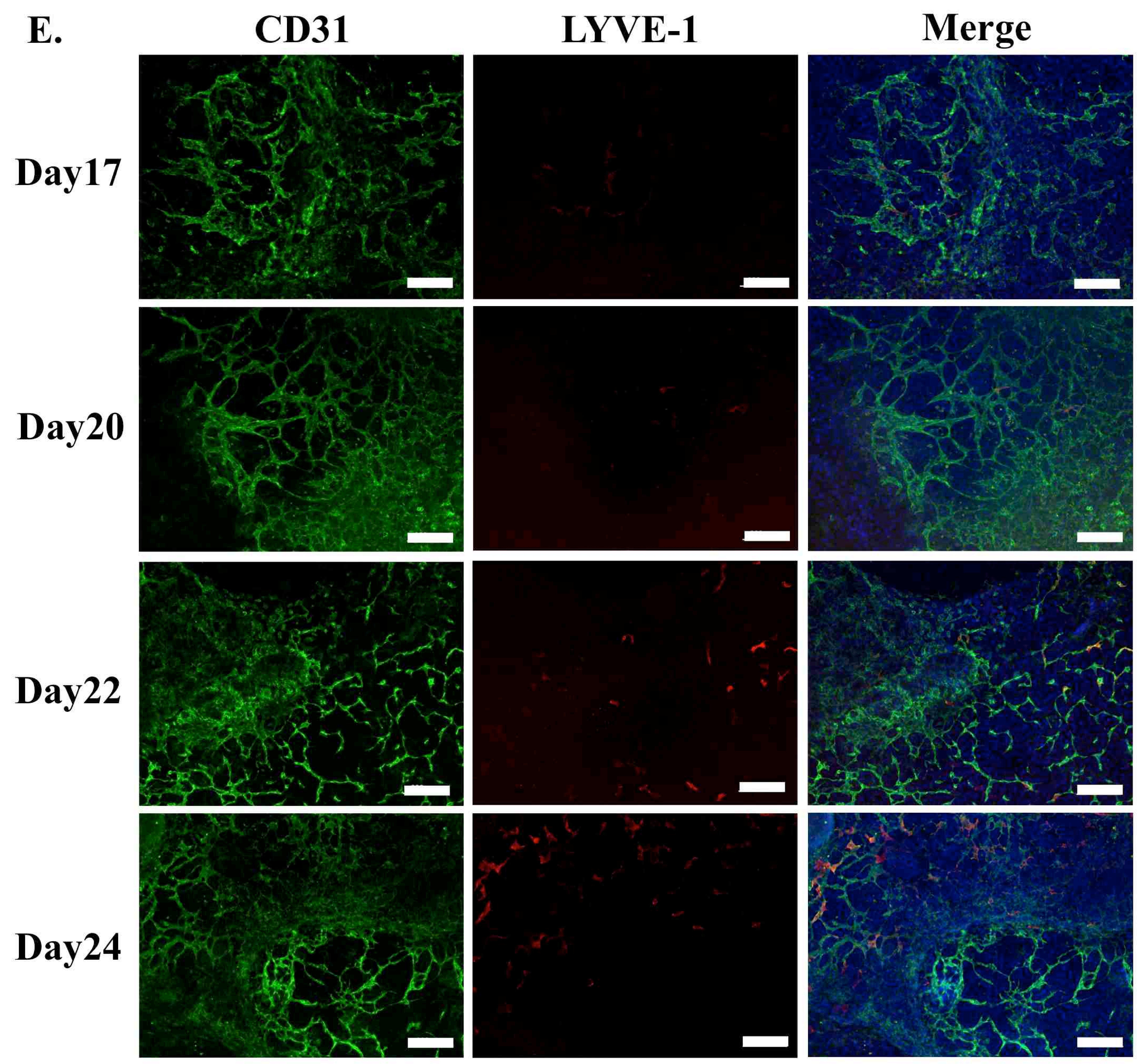

Fig 1. 


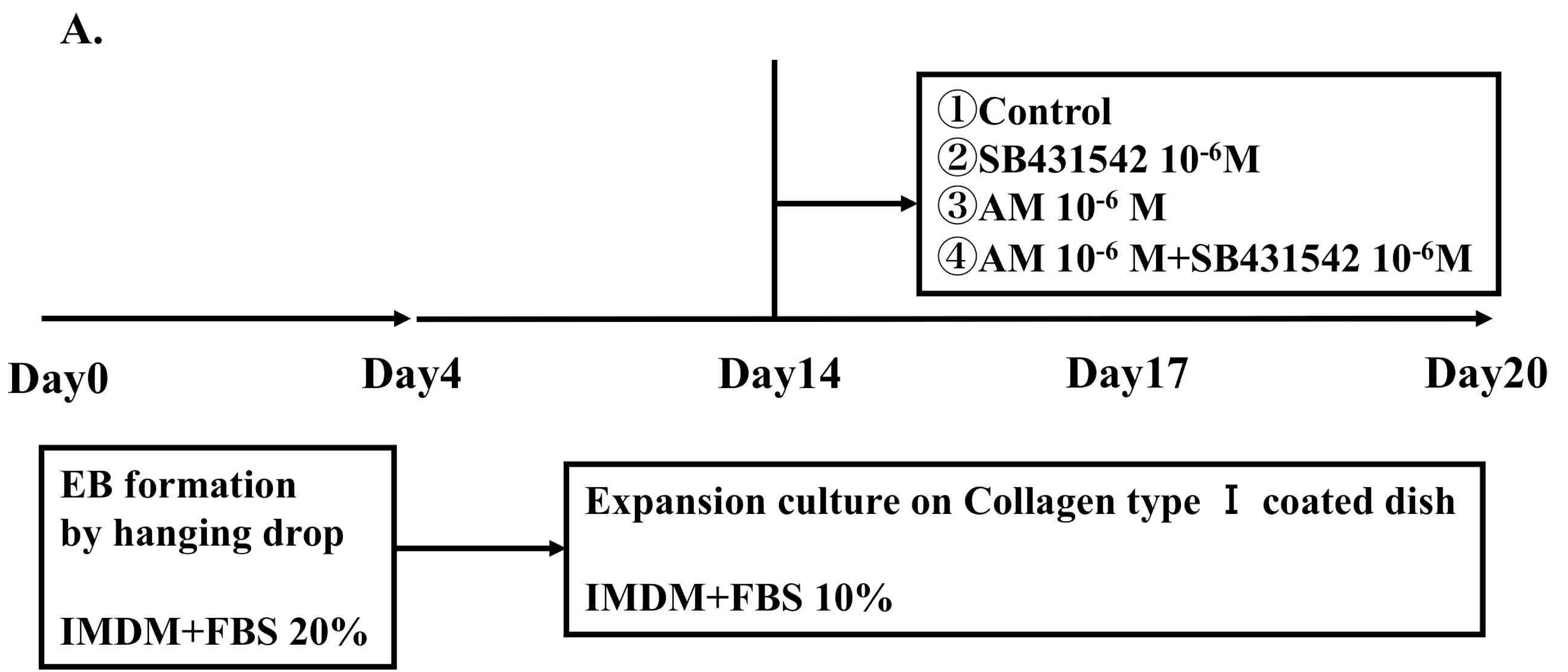

Fig 2. 


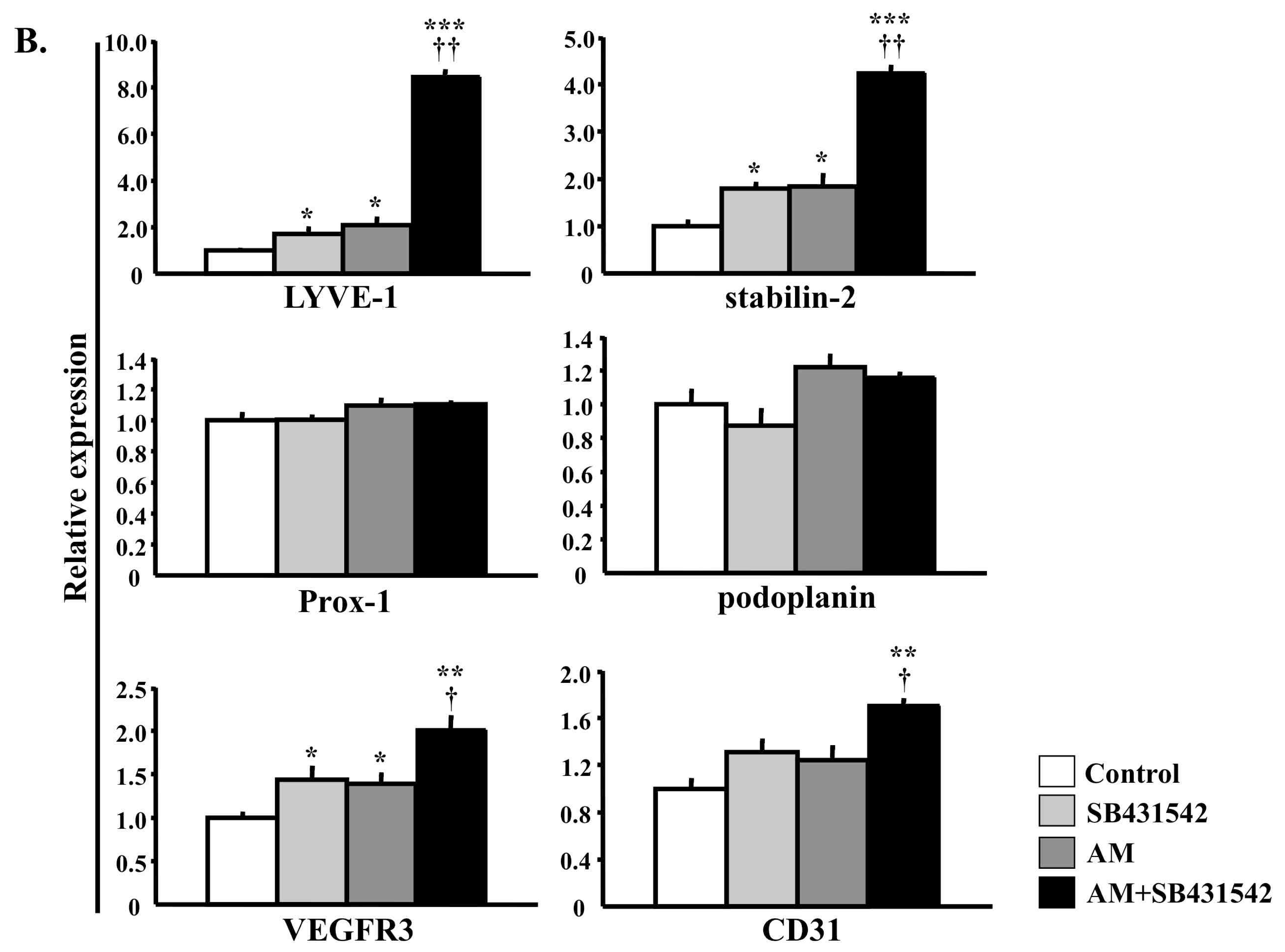

Fig 2. 


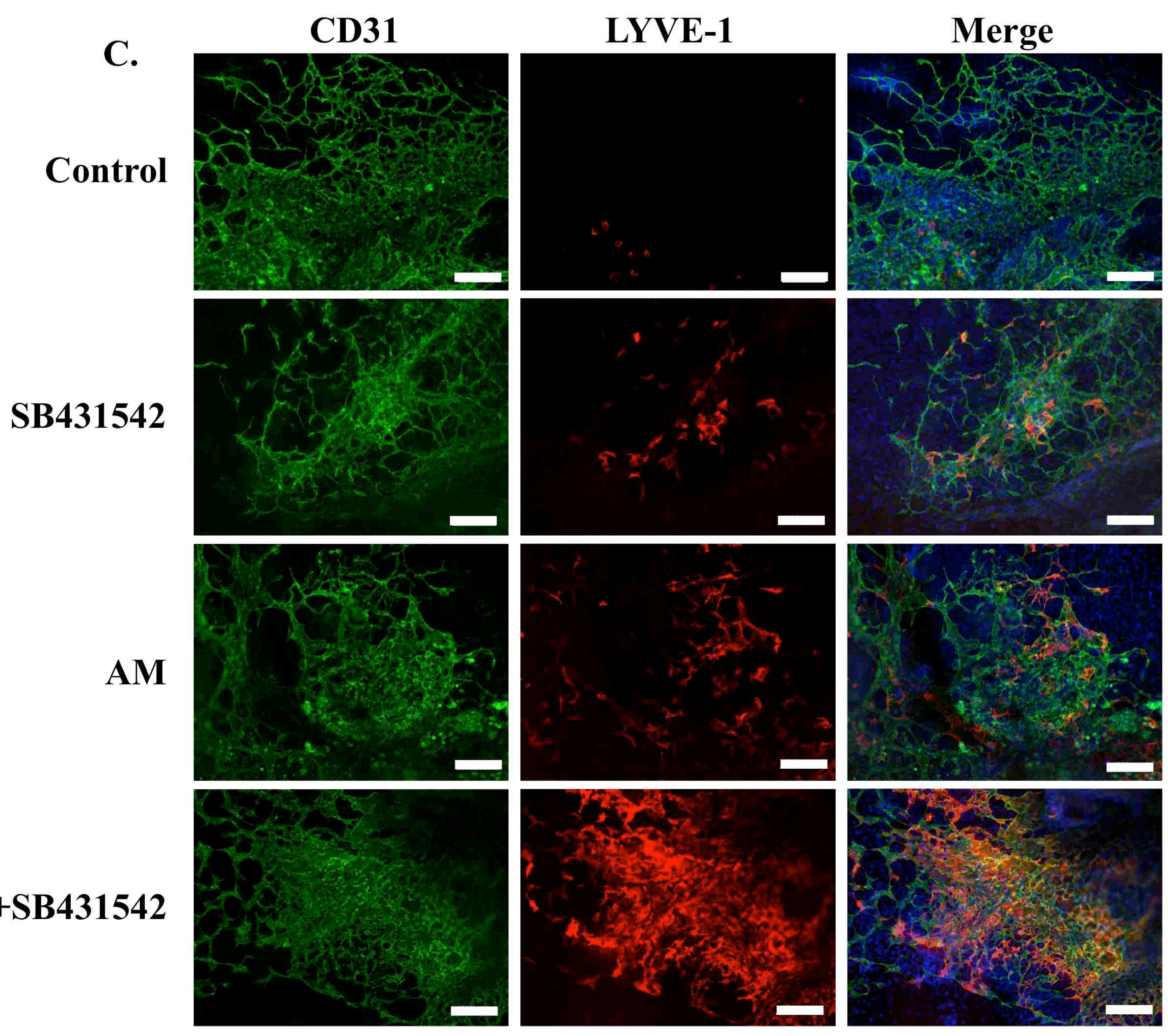

Fig 2. 
D.

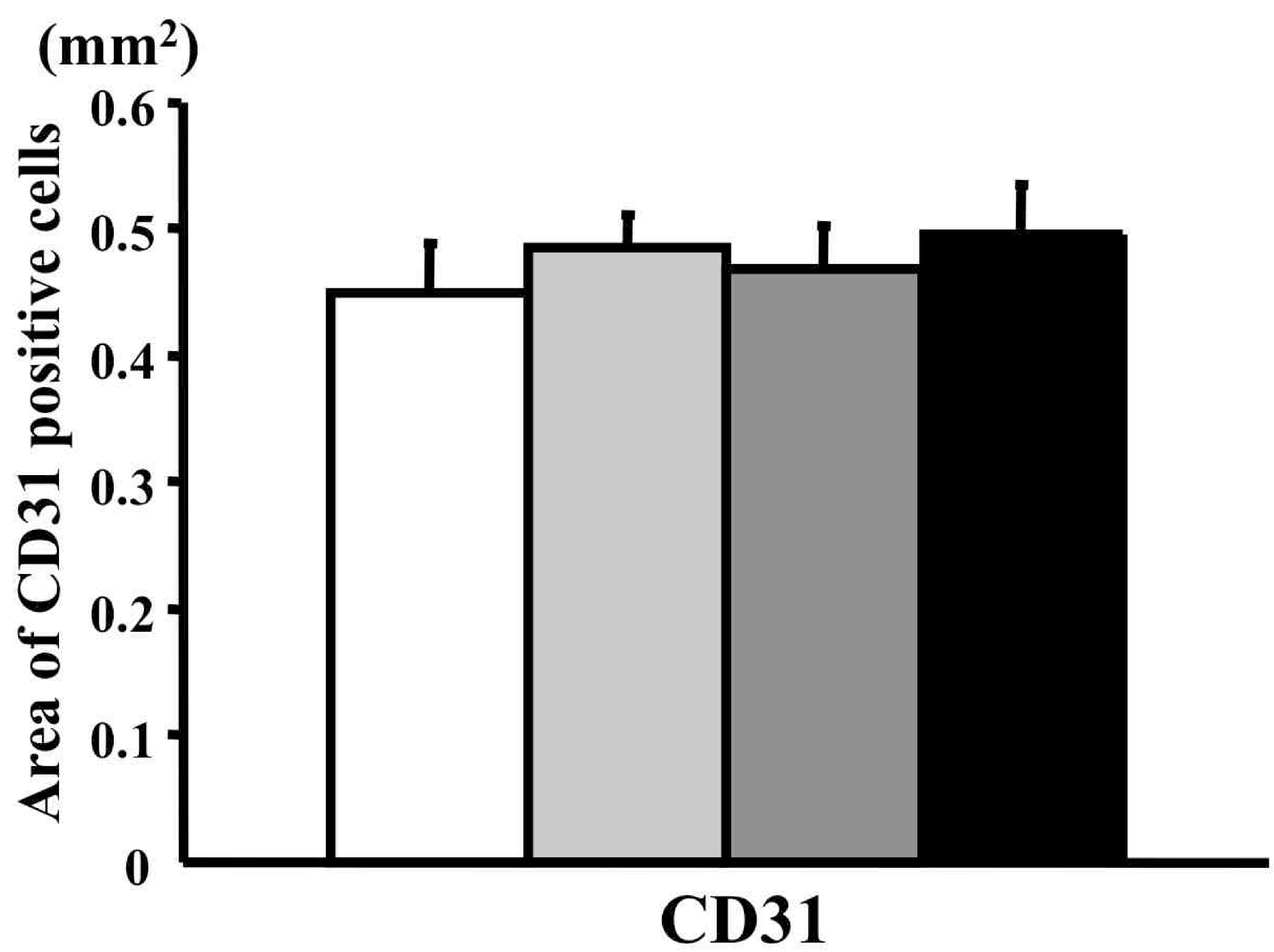

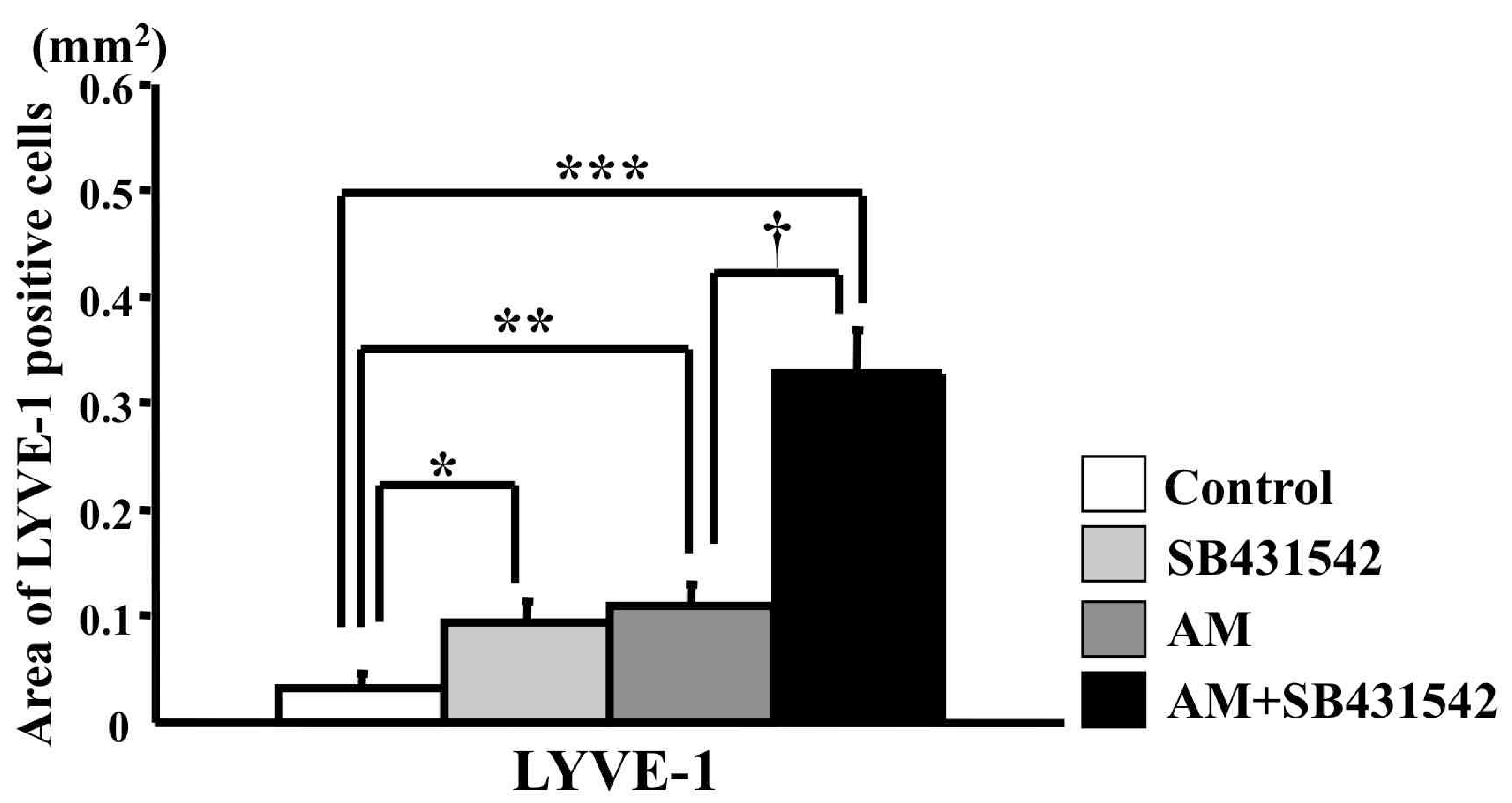


A.

Control

AM+SB431542

Primary -cultured LSEC stabilin-2
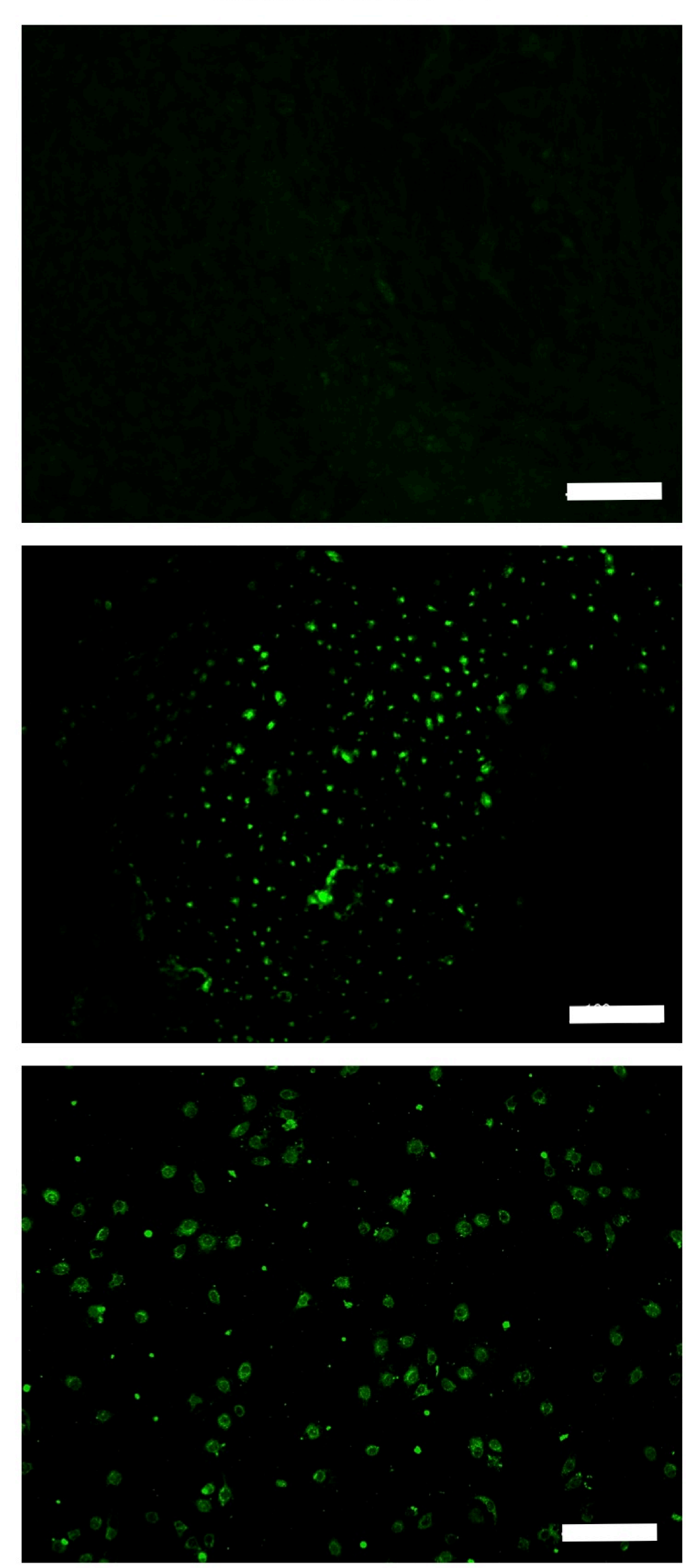

LYVE-1
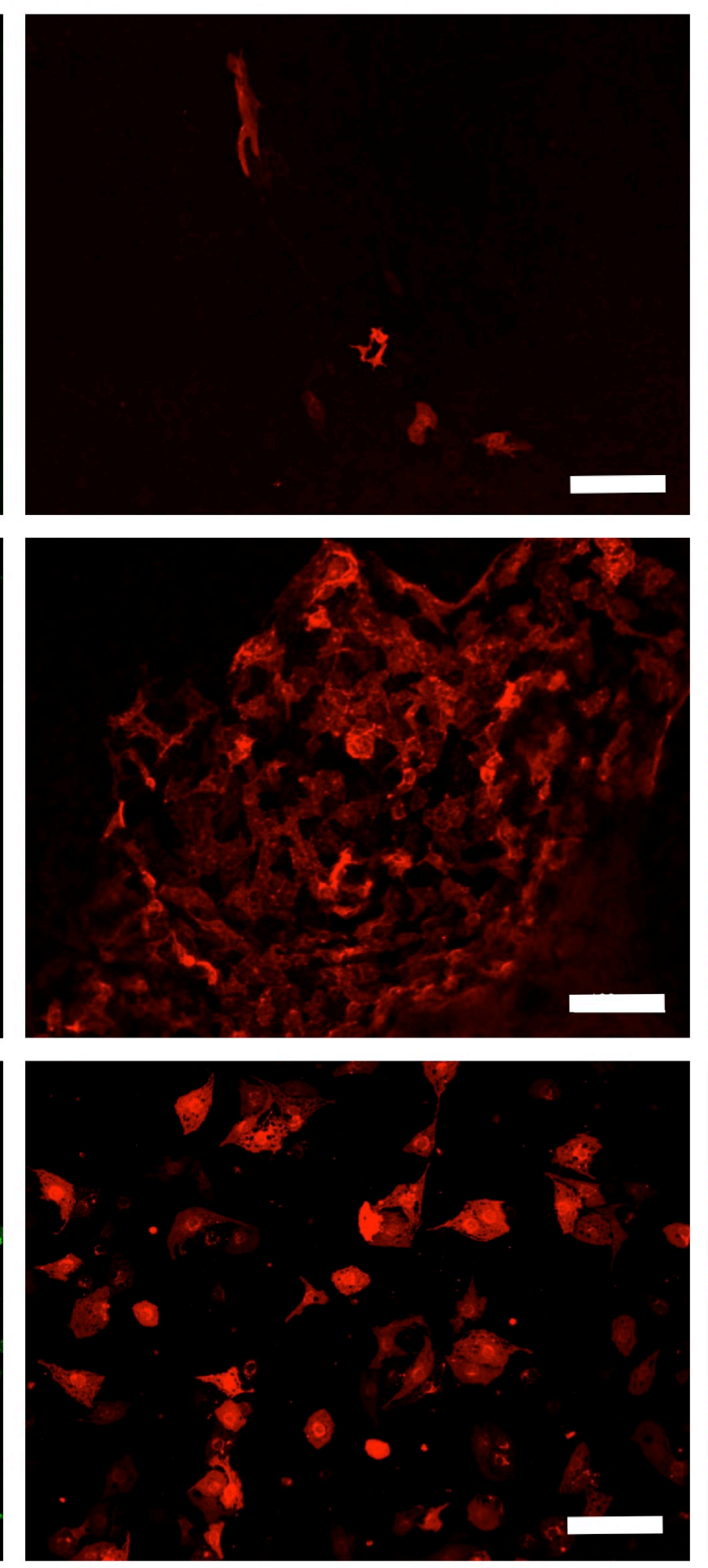

Merge
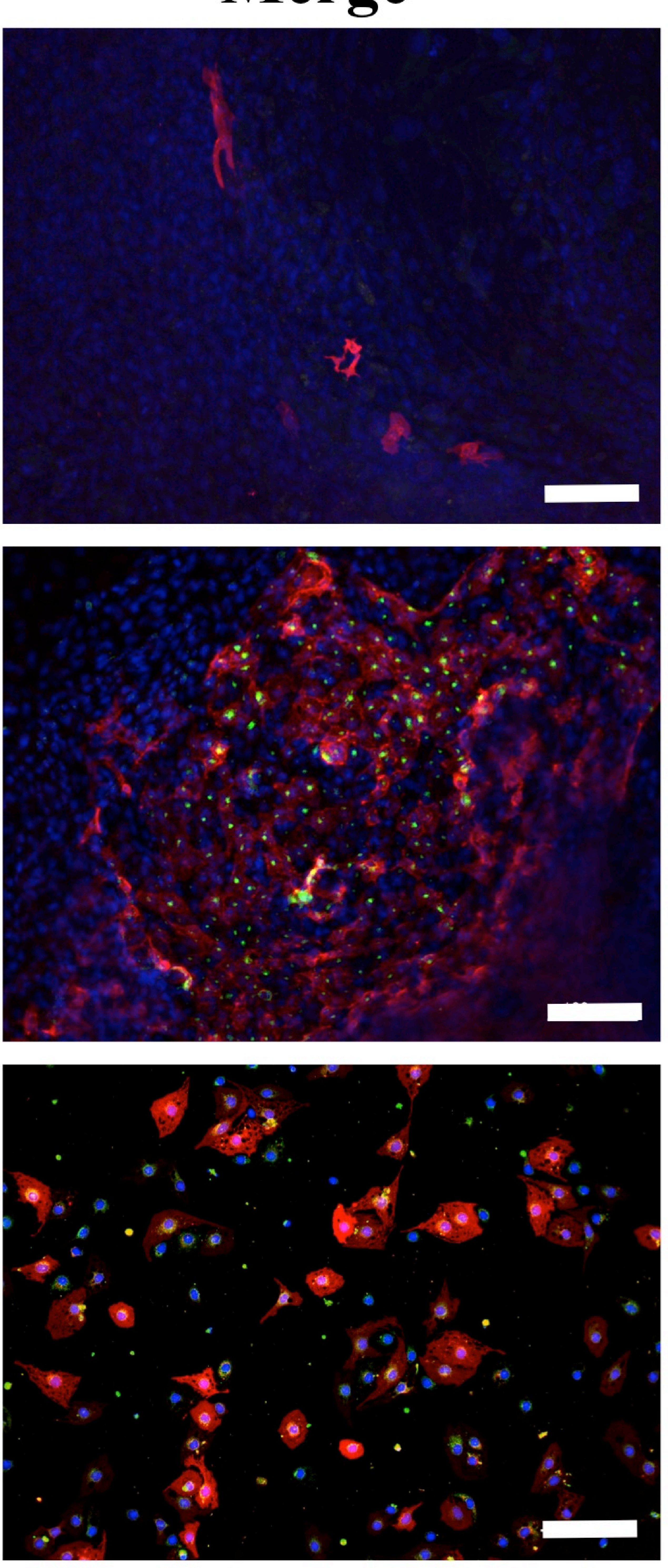

Fig 3. 
B.

stabilin-2

LYVE-1

Merge

AM+SB431542

Control

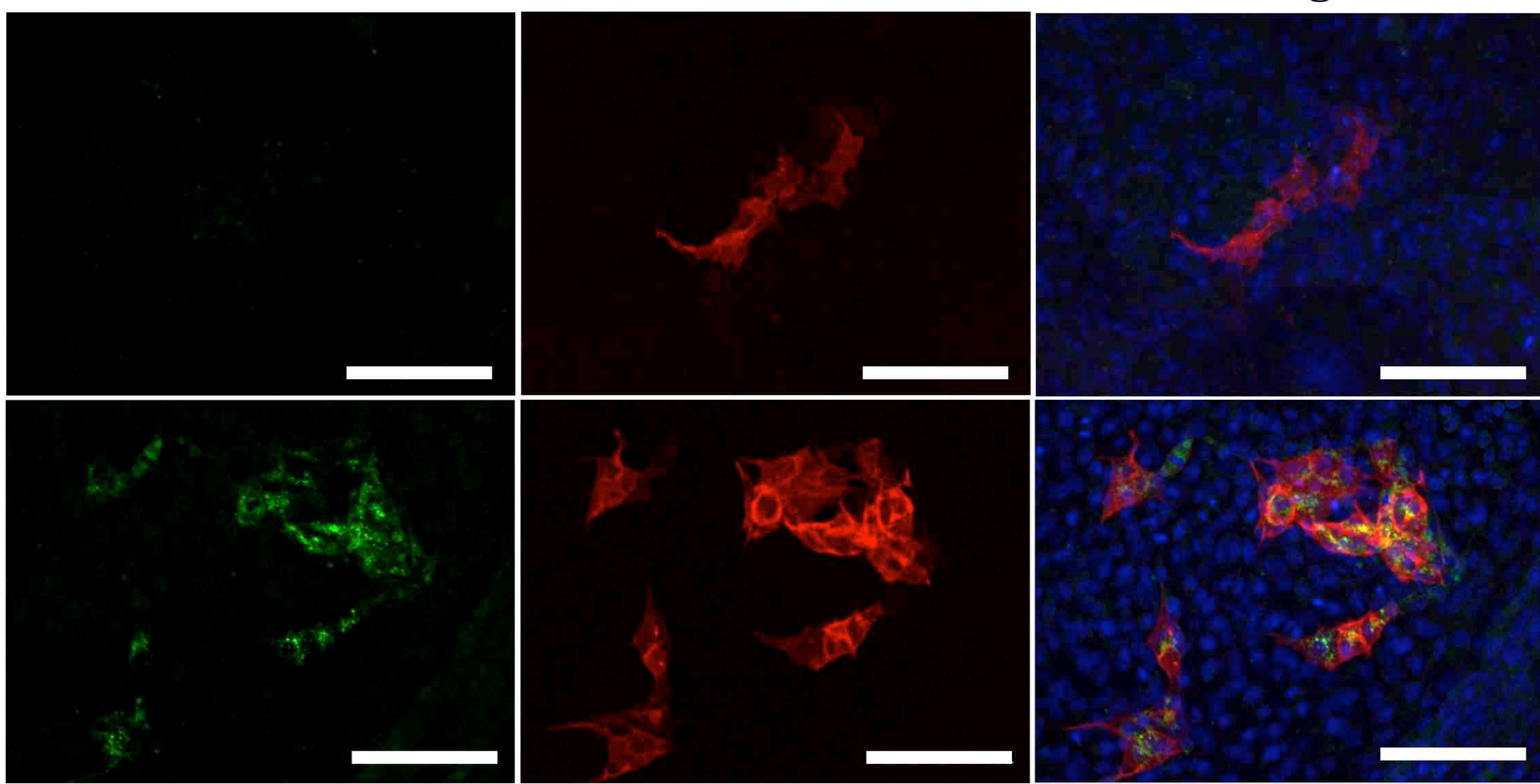

Fig 3. 
C.

$* *$
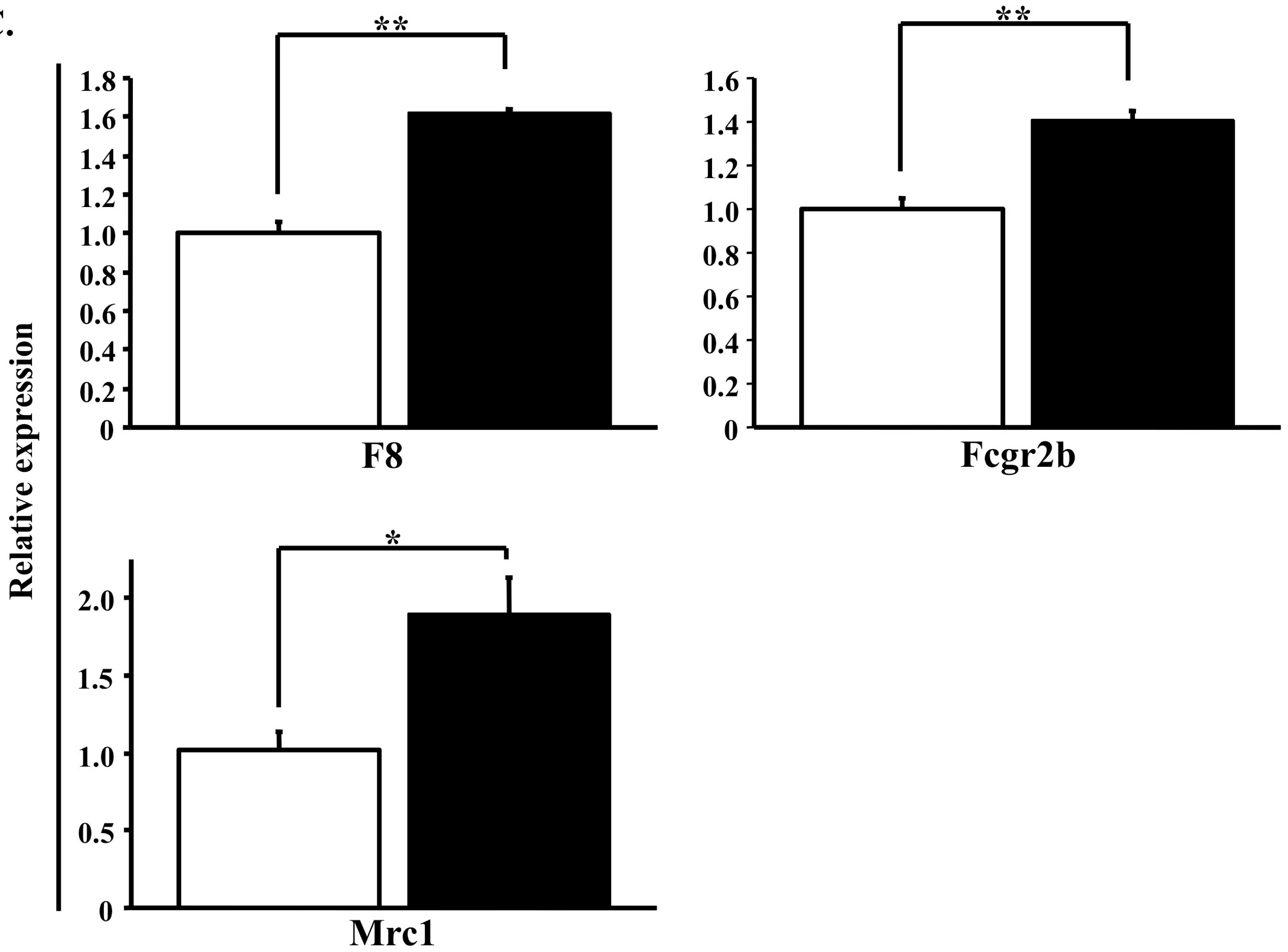

Fig 3. 


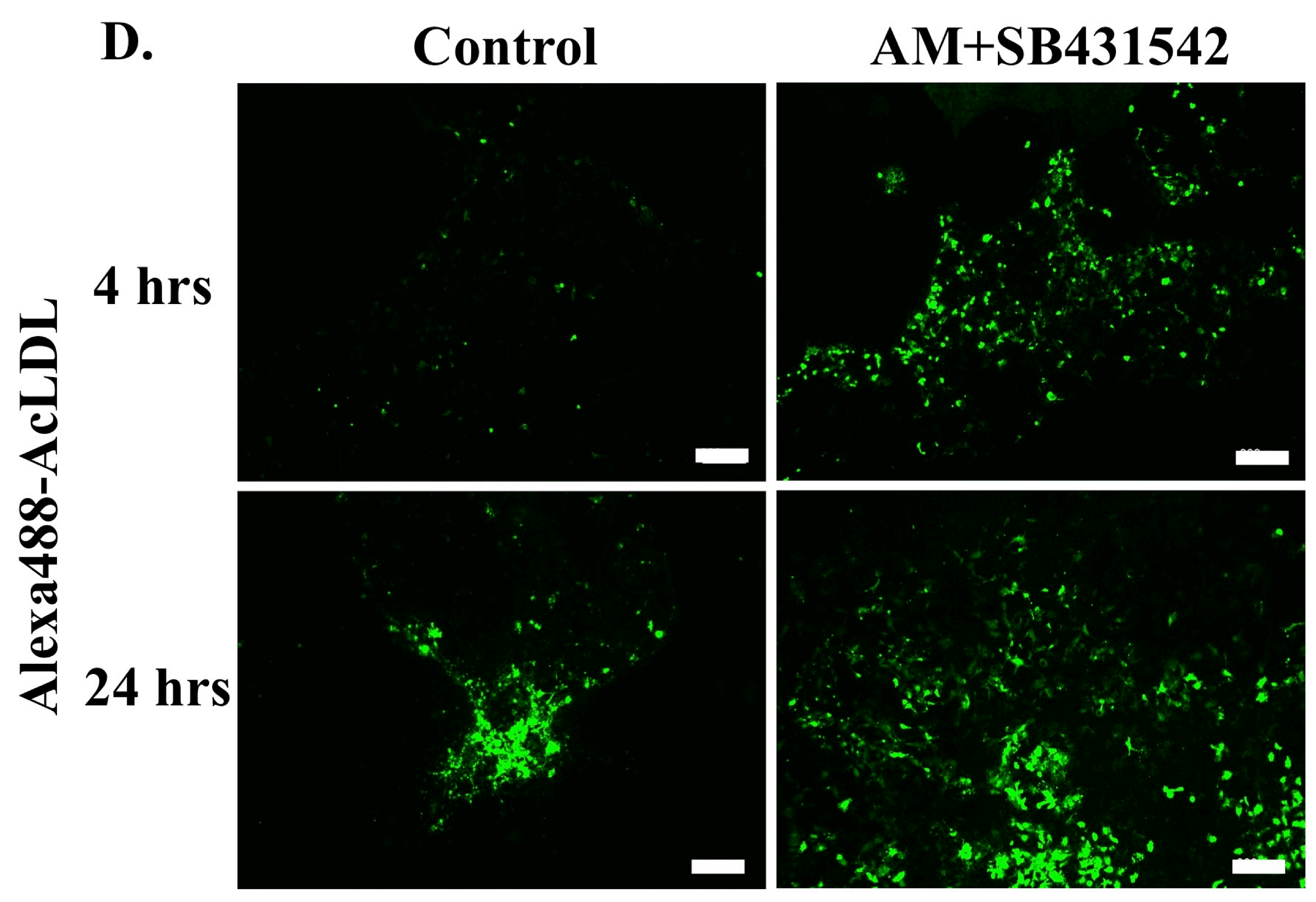

Fig 3. 


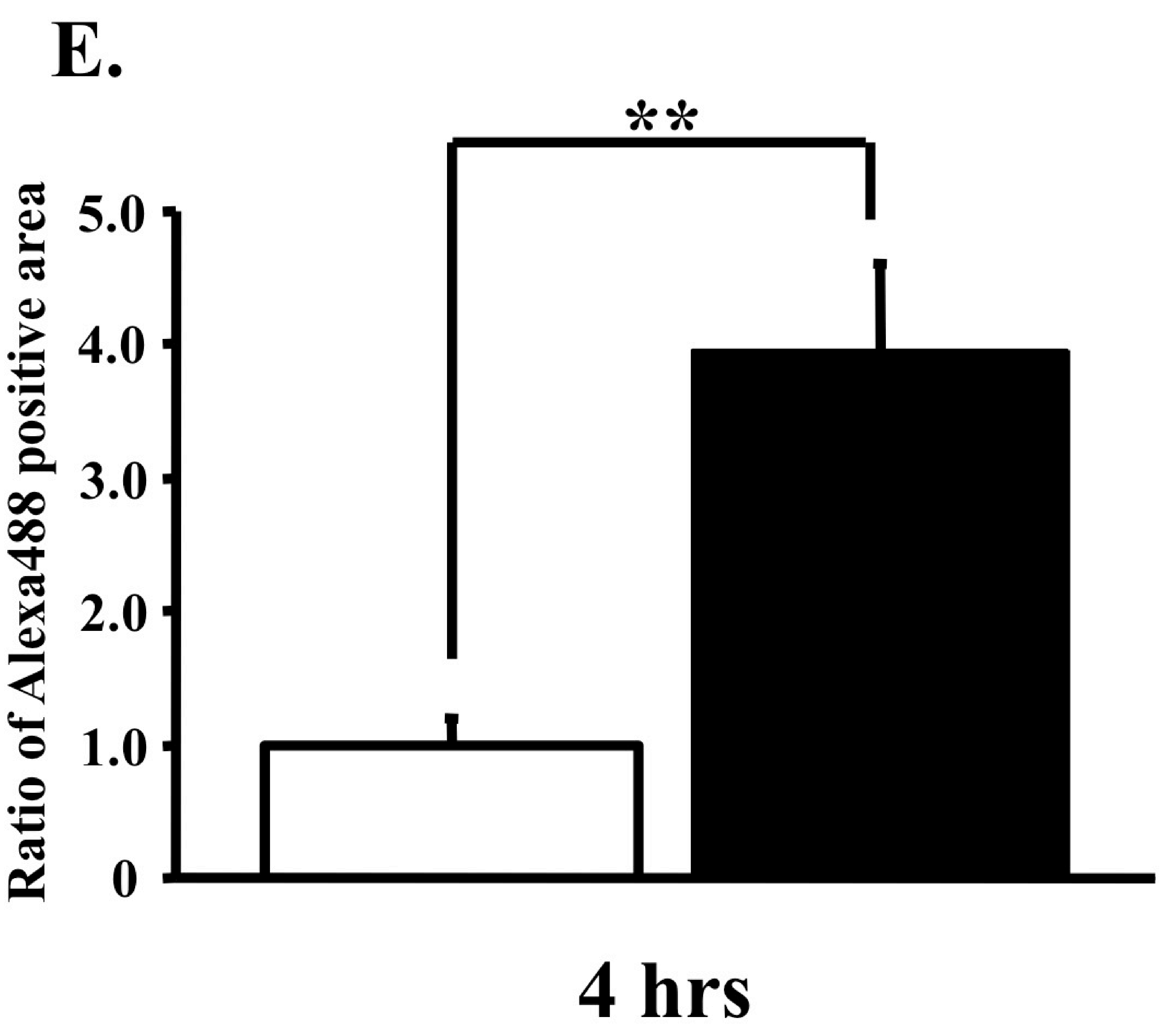

Fig 3. 
F.

Control

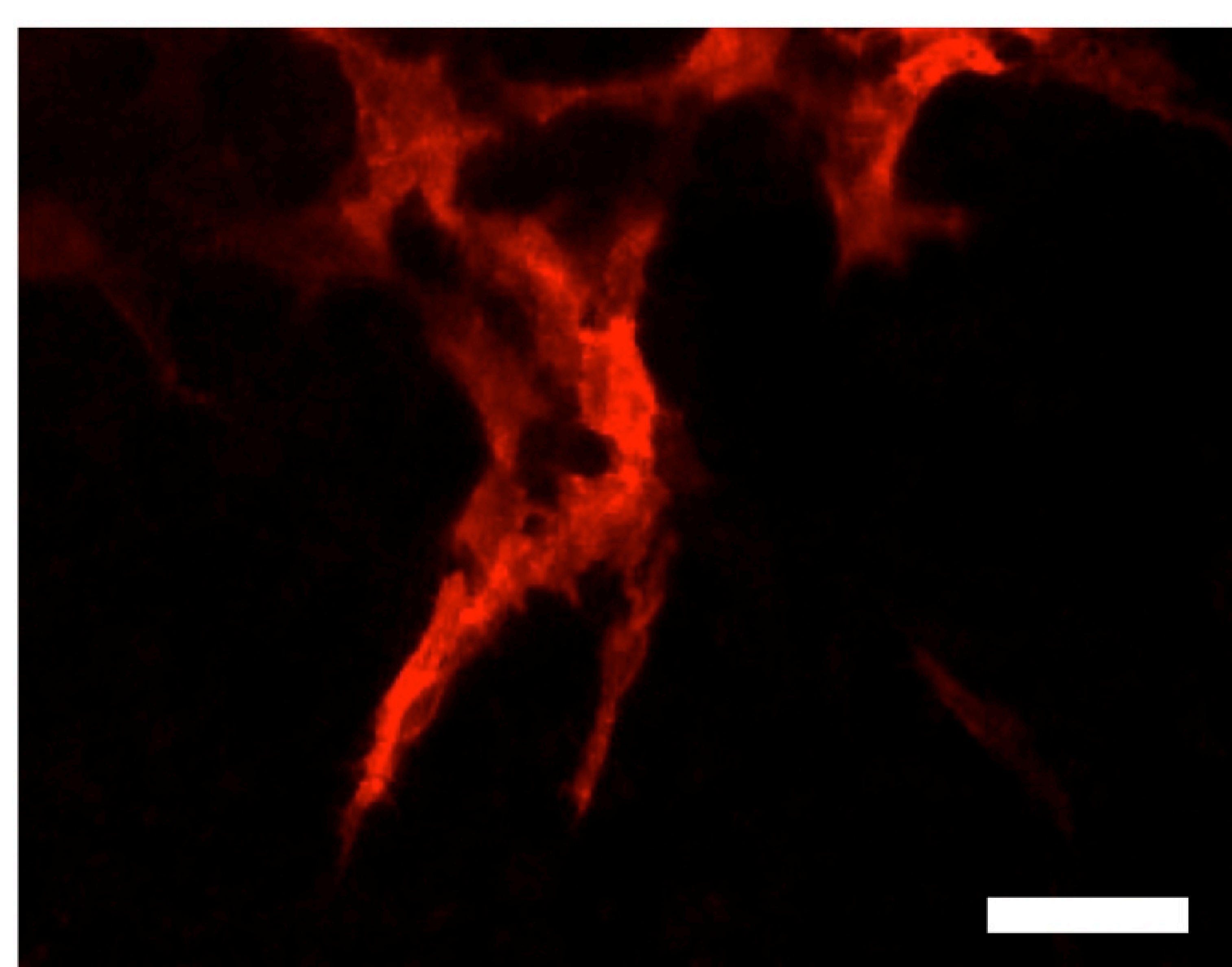

EM

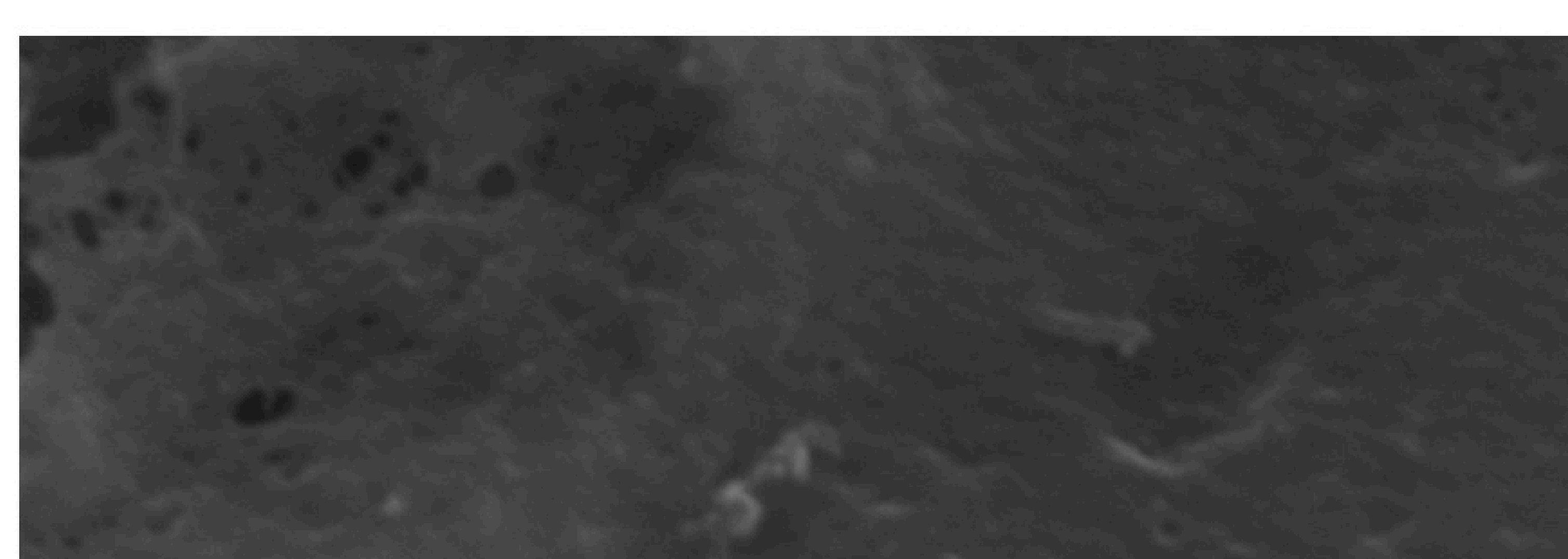

$\mathrm{AM}+\mathrm{SB} 431542$
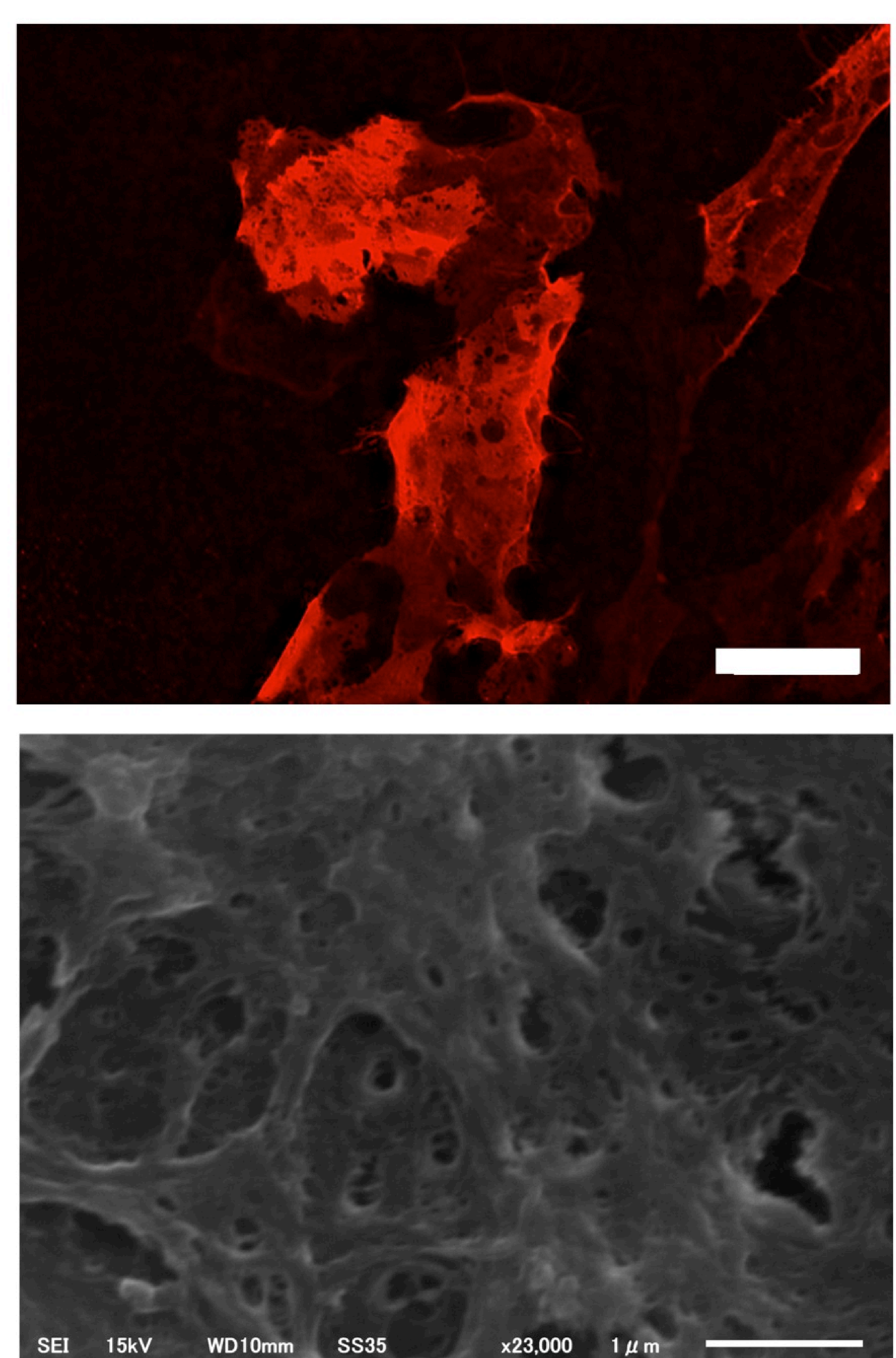

Primary-cultured

LSEC

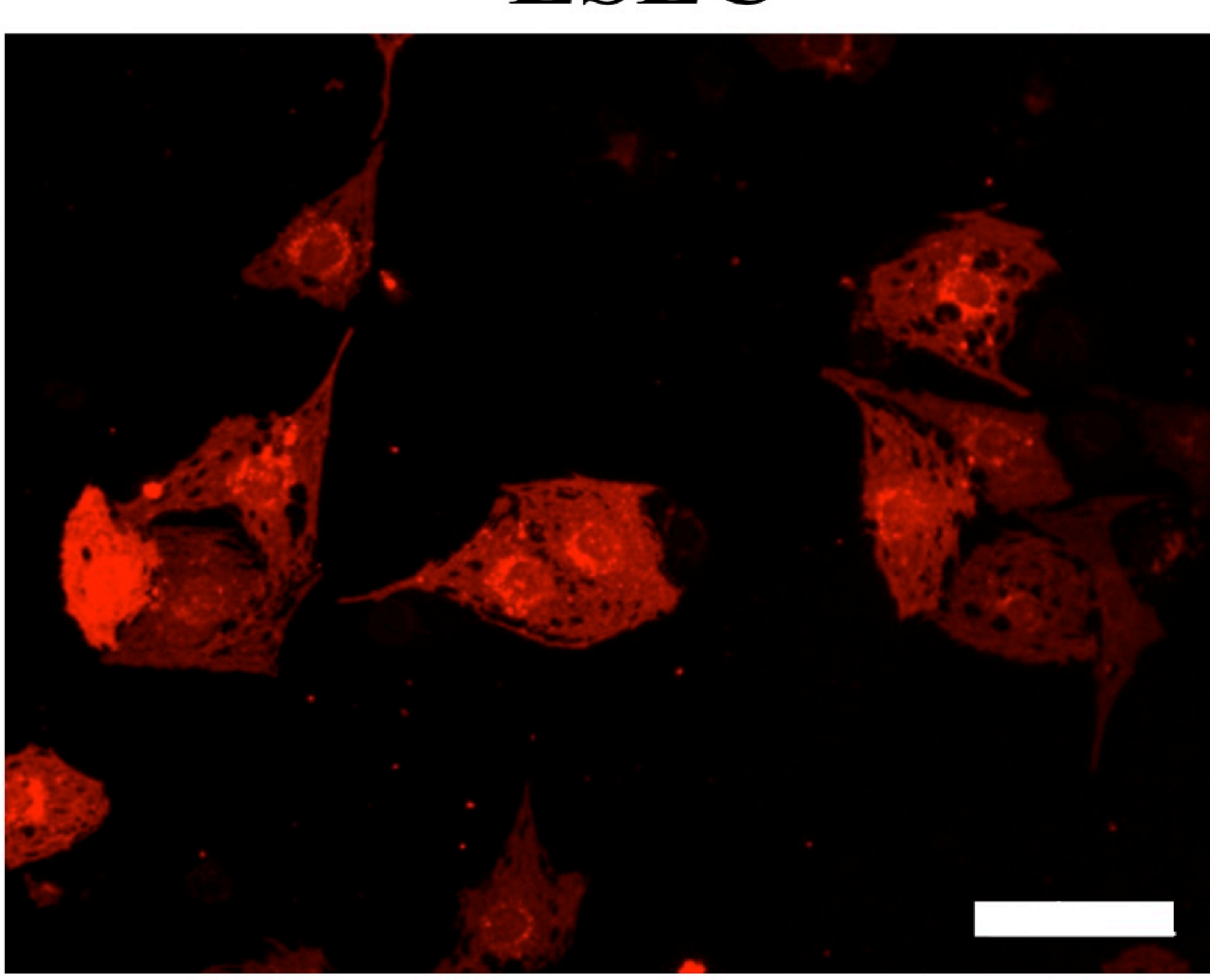

Fig 3. 
A.

E14.5 Liver

Adult Liver
CD31

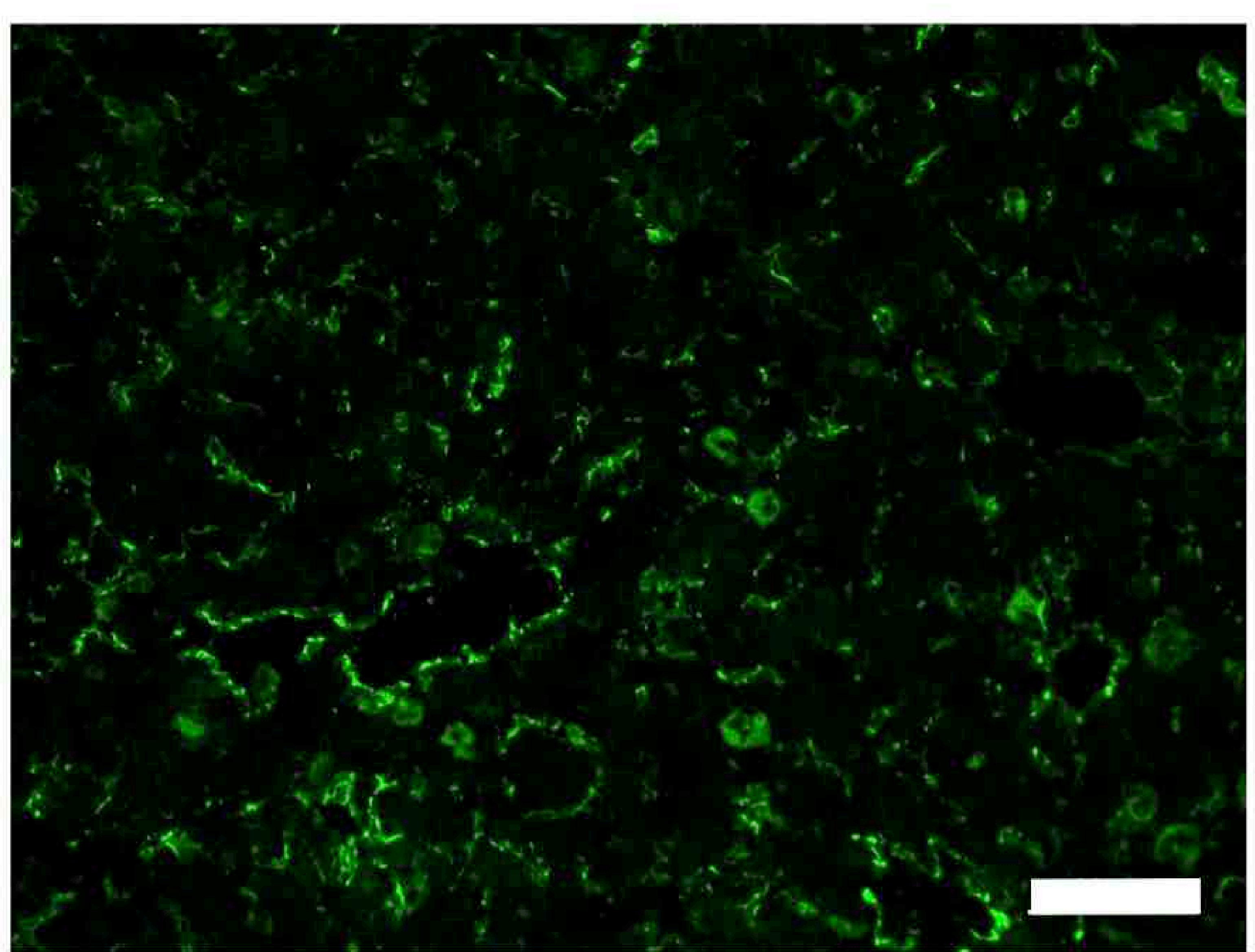

LYVE-1

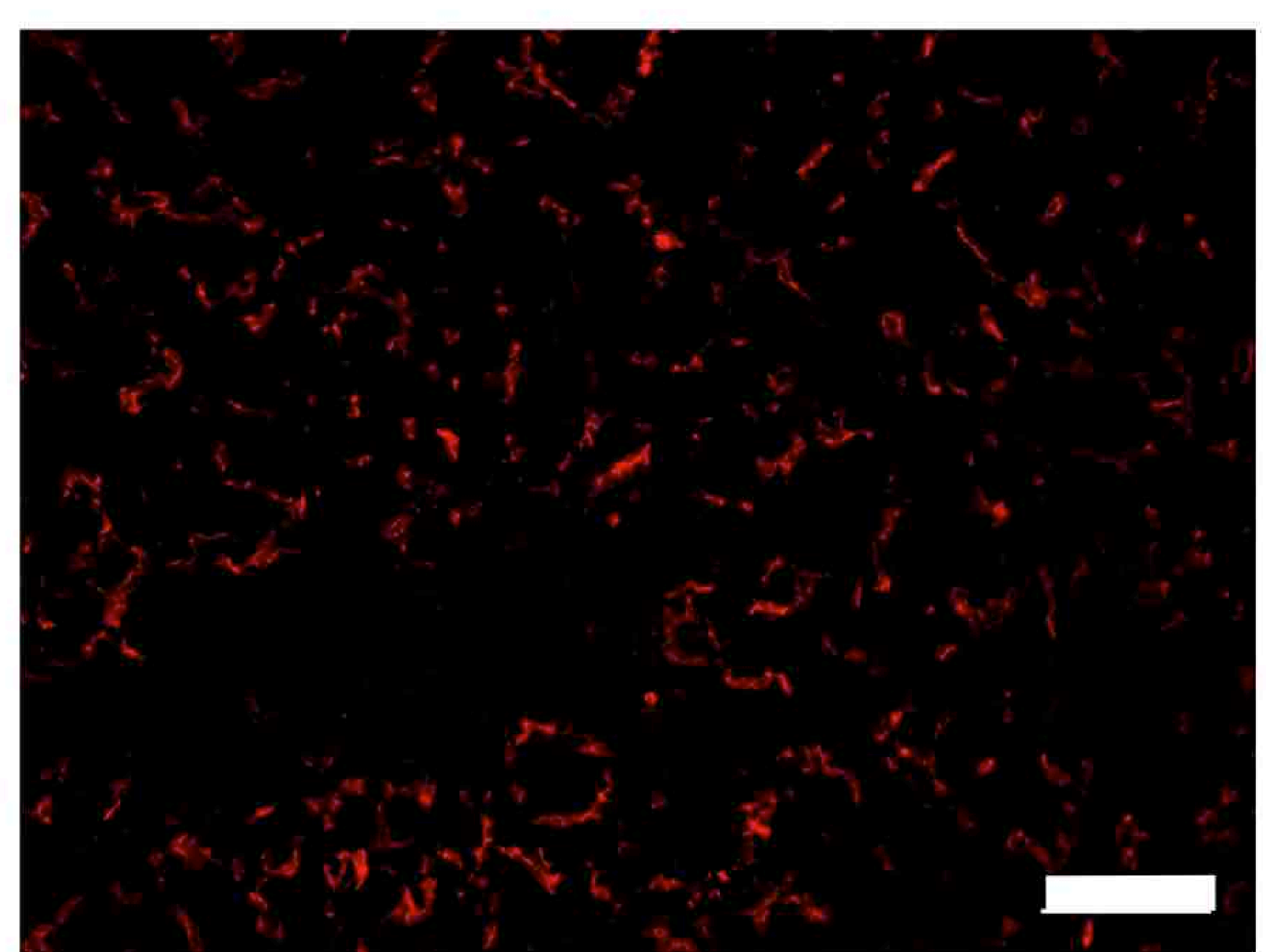

Merge

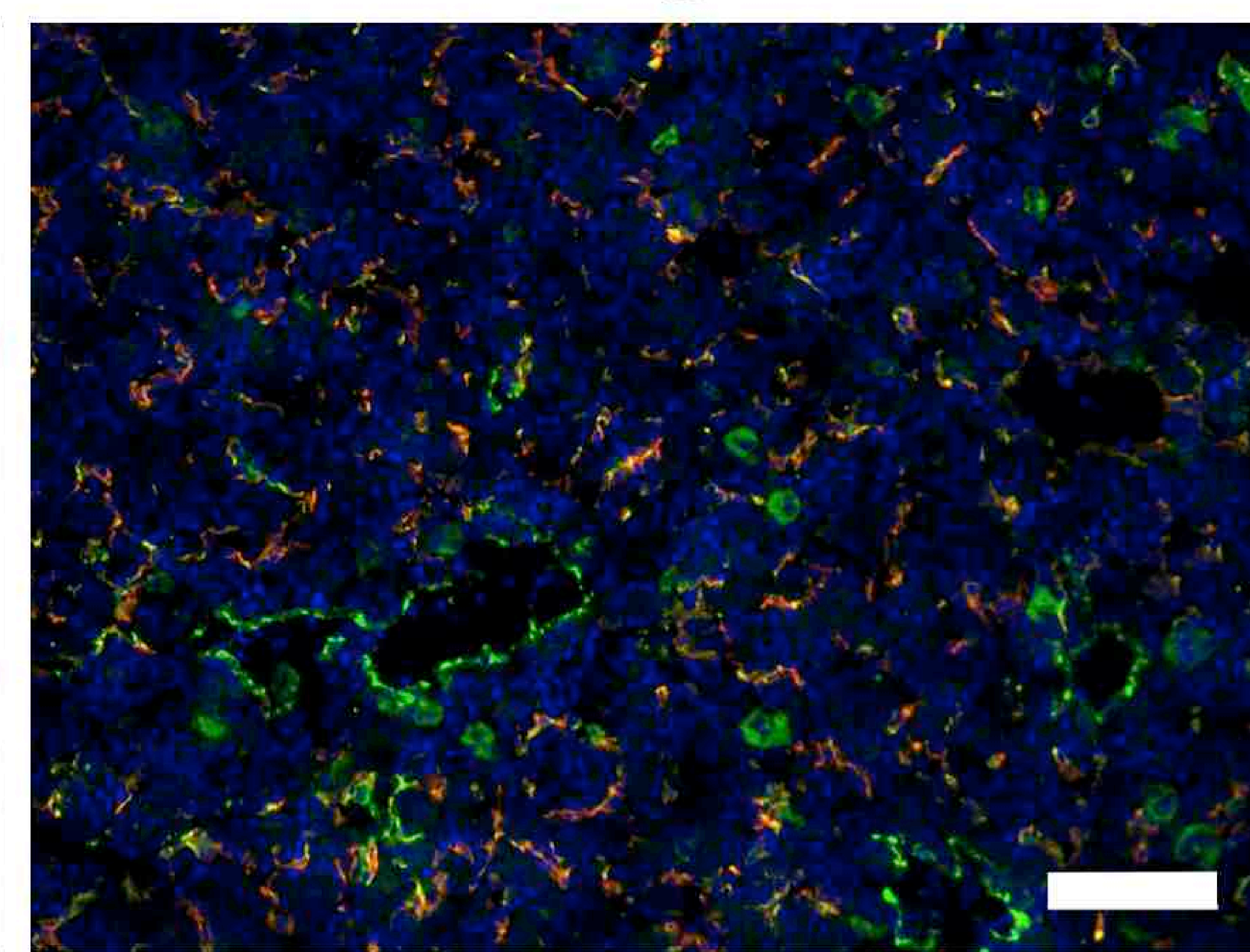

Fig 4. 


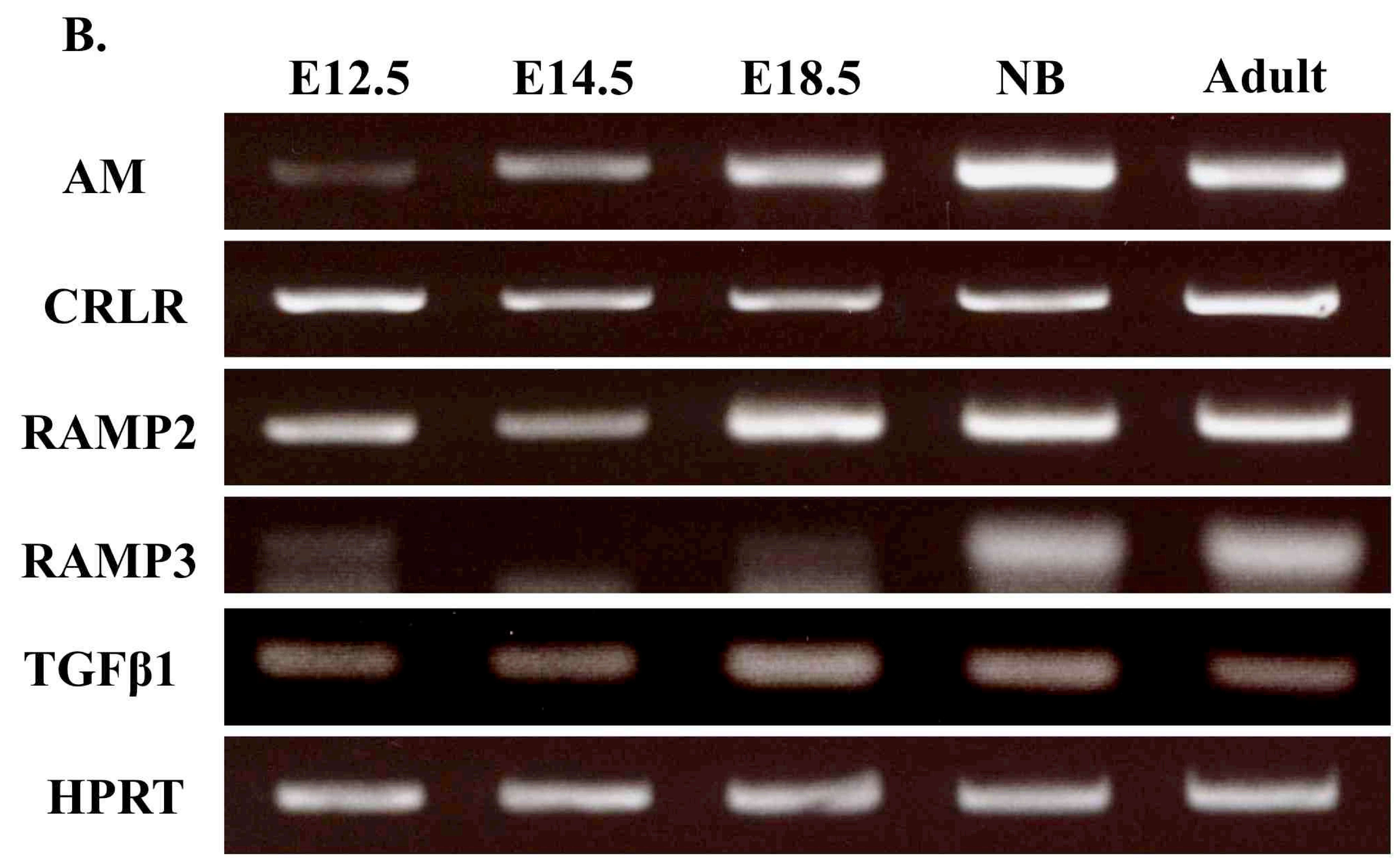

Fig 4. 
C.

CD31

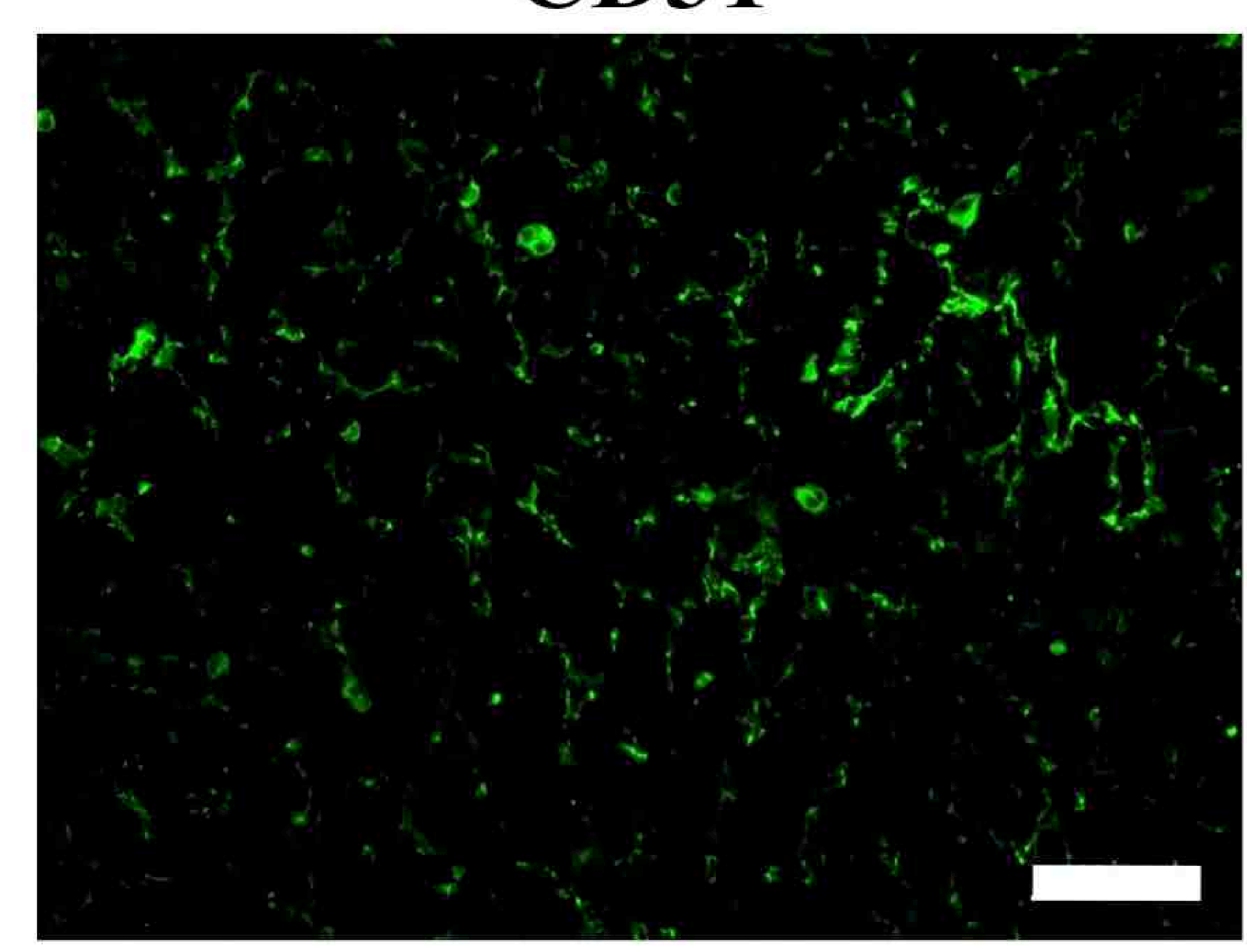

LYVE-1

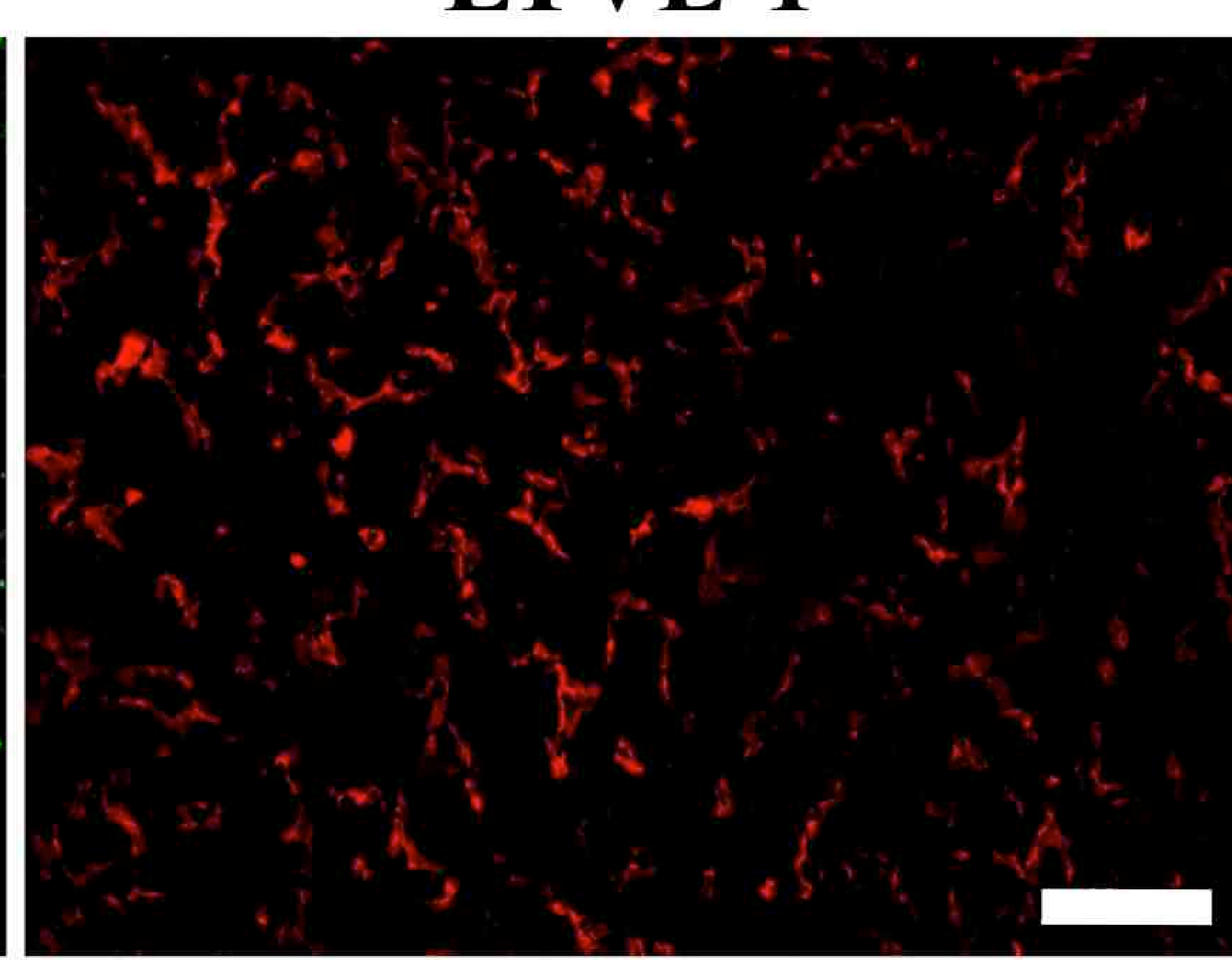

Merge

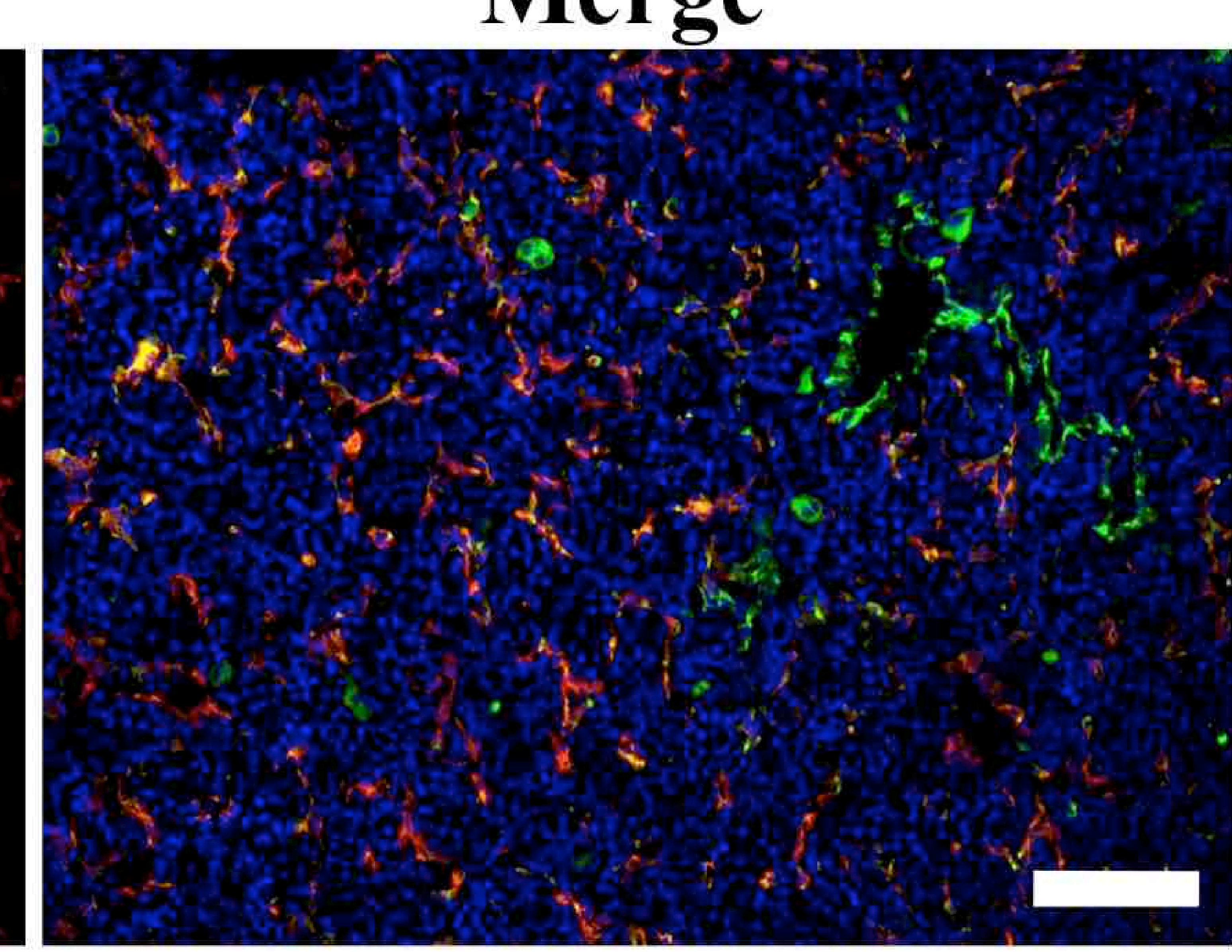

RAMP2

-/-
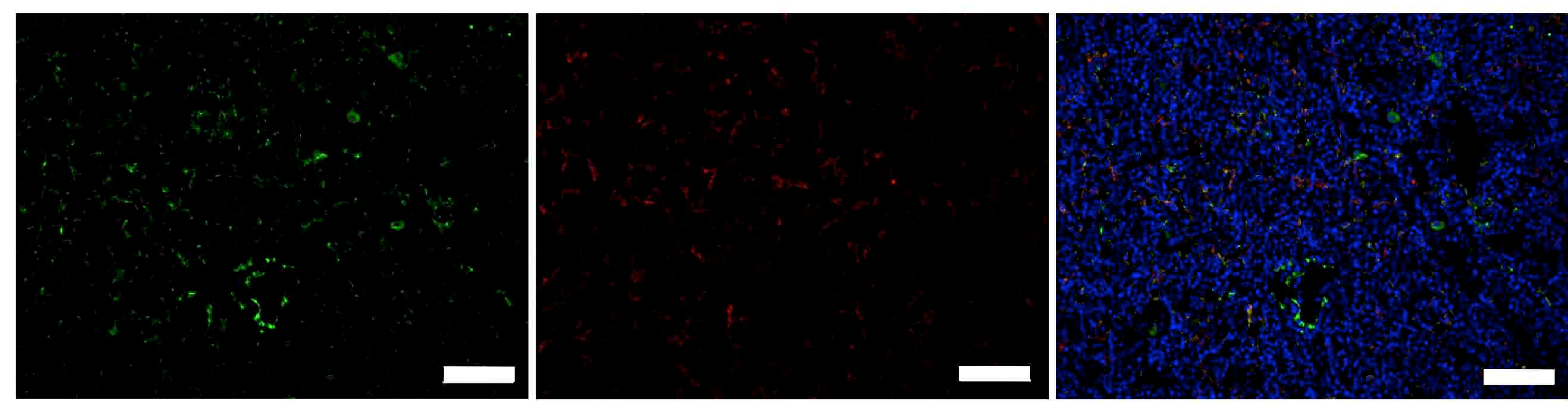

Fig 4. 
D.

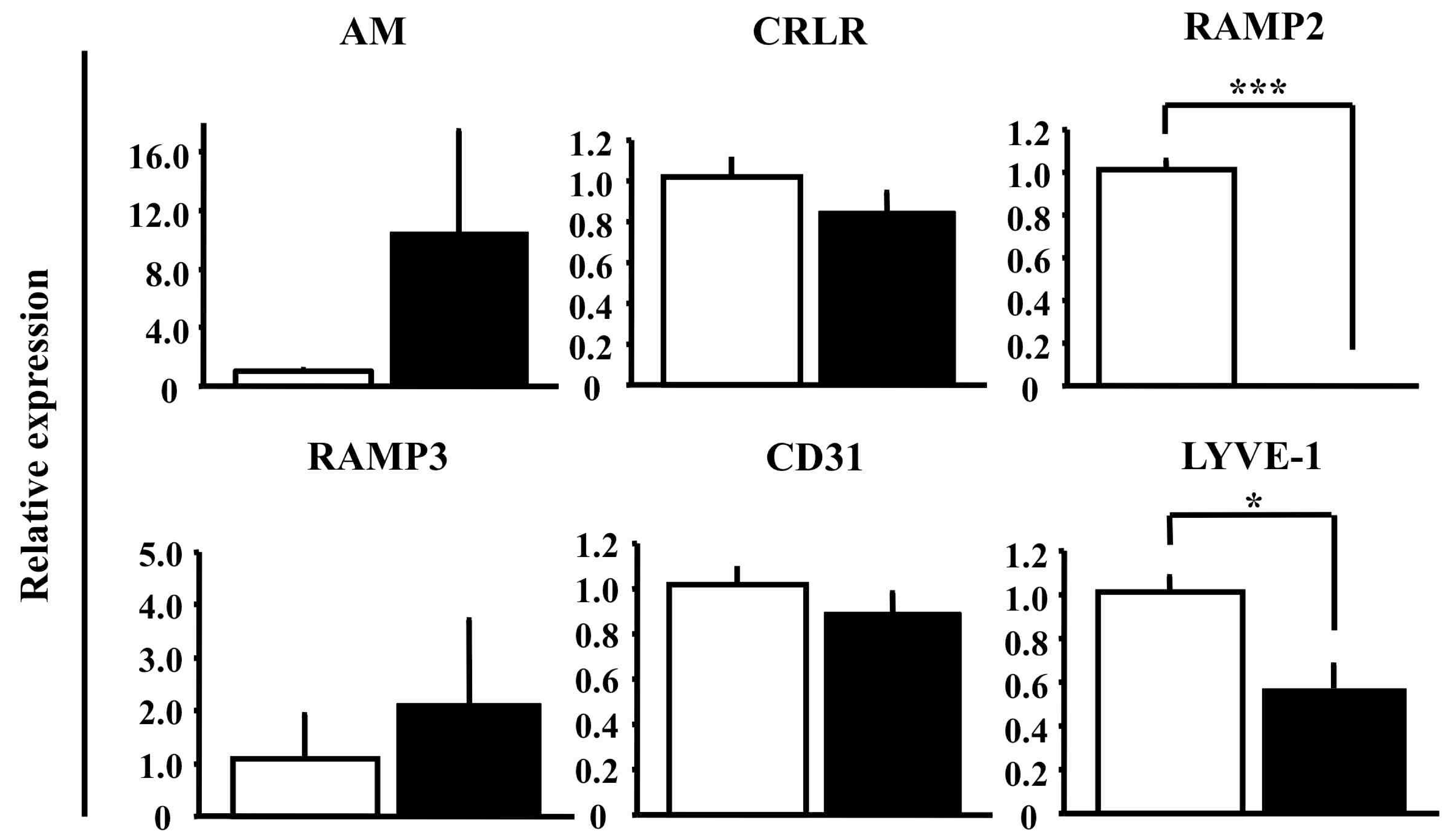

Fig 4. 
TABLE 1.

For qRT-PCR

\begin{tabular}{|l|l|l|}
\hline LYVE-1 & $\begin{array}{l}\text { Forward } \\
\text { Reverse }\end{array}$ & $\begin{array}{l}\text { AAGCAGCTGGGTTTGGAGGT } \\
\text { CACCAAAGAAGAGGAGAGCCA }\end{array}$ \\
\hline stabilin-2 & $\begin{array}{l}\text { Forward } \\
\text { Reverse }\end{array}$ & $\begin{array}{l}\text { GCTCGAGACAAAACCACTTAGTGA } \\
\text { CCCGATGAAAATGGATCTCTTC }\end{array}$ \\
\hline Prox-1 & $\begin{array}{l}\text { Forward } \\
\text { Reverse }\end{array}$ & $\begin{array}{l}\text { CGGGTTGAGAATATCATTC } \\
\text { TCTTTCGTTTTCATTGCCCC }\end{array}$ \\
\hline podoplanin & $\begin{array}{l}\text { Forward } \\
\text { Reverse }\end{array}$ & $\begin{array}{l}\text { TGGCAAGGCACCTCTGGTA } \\
\text { TGAGGTGGACAGTTCCTCTAAGG }\end{array}$ \\
\hline VEGFR3 & $\begin{array}{l}\text { Forward } \\
\text { Reverse }\end{array}$ & $\begin{array}{l}\text { AAGGCCTGCCCATGCA } \\
\text { TCGCCAGGGTCCATGATG }\end{array}$ \\
\hline F8 & Forward & TGCCTGACCCGCTATTATTC \\
Reverse & AGCGTTGCATGTTCTCTGTG \\
\hline Fcgr2b & Forward & CCCTGGGAACTCTTCTACCC \\
Reverse & Forward \\
Reverse & ATGCAGCCAGTCAGAAATCA \\
\hline
\end{tabular}


TABLE 2.

For RT-PCR

\begin{tabular}{|l|l|l|}
\hline VEGF & $\begin{array}{l}\text { Forward } \\
\text { Reverse }\end{array}$ & $\begin{array}{l}\text { CAGGCTGCTGTAACGATGAA } \\
\text { AATGCTTTCTCCGCTCTGAA }\end{array}$ \\
\hline AM & $\begin{array}{l}\text { Forward } \\
\text { Reverse }\end{array}$ & $\begin{array}{l}\text { TCGAATTCATCGCCACAGAATGAAGCTGGT } \\
\text { TCGAATTCTATATCCTAAAGAGTCTGGAGA }\end{array}$ \\
\hline CRLR & Forward & TAAGTTGCCAACGGATCACA \\
& Reverse & CCCTTGCATGTCACTGATTG \\
\hline Ramp2 & Forward & CATCCCACTGAGGACAGCCT \\
& Reverse & GATCATGGCCAGGAGCACAT \\
\hline Ramp3 & $\begin{array}{l}\text { Forward } \\
\text { Reverse }\end{array}$ & $\begin{array}{l}\text { TCGAATTCATCTTAGTTGGCCATGAAGAC } \\
\text { ATACCTGGGCACACTCACCACAA }\end{array}$ \\
\hline TGF $\beta 1$ & $\begin{array}{l}\text { Forward } \\
\text { Reverse }\end{array}$ & $\begin{array}{l}\text { CCCGAAGCGGACTACTATGC } \\
\text { TAGATGGCGTTGTTGCGGT }\end{array}$ \\
\hline ALK1 & Forward & TGACCTCAAGAGTCGCAATG \\
Reverse & FTCGGGTGCCATGTATCTTT \\
\hline ALK5 & Forward & GGCGAAGGCATTACAGTGTT \\
& Reverse & FGCACATACAAATGGCCTGT \\
\hline HPRT & Forward & $\begin{array}{l}\text { GTTGGATACAGGCCAGACTTTGTTG } \\
\text { GAGGGTAGGCTGGCCTATAGGCT }\end{array}$ \\
\hline
\end{tabular}




\section{Supplemental Table 1. \\ Genes upregulated in EBs treated with AM and SB431542 (>three fold)}

\begin{tabular}{|c|c|c|c|}
\hline Gene & $\begin{array}{l}\text { NCBI } \\
\text { Ref.Seq. }\end{array}$ & Description & $\begin{array}{l}\text { fold } \\
\text { change }\end{array}$ \\
\hline Sprr3 & NM 011478 & sm all pro line-rich prote in 3 [Source M arkerSym bo lA cc M G I:1330237] & 12.20 \\
\hline Myll & NM 021285 & m yos n, light po lypeptide 1 [Source M arkerSym bo lA cc M G I97269] & 7.63 \\
\hline Adra2b & NM 009633 & adrenergic receptor, a pha 2b [Source M arkerSym bo lAcc M G I87935] & 7.19 \\
\hline Krt4 & NM 008475 & keratin 4 [Source M arkerSym bo lA cc M G I96701] & 5.91 \\
\hline Tesp2 & - & testicular serine protease 2 [Source M arkerSym bo l'Acc M G I:1270857] & 5.79 \\
\hline Tnnc2 & NM 009394 & tropon in C 2, fast [Source M arkerS ym bo lA cc M G I98780] & 5.56 \\
\hline S lc4a1 & NM 011403 & so lute carrier fam ily 4 (an ion exchanger), m em ber 1 [Source M arkerSym bo lA cc M G I:109393] & 5.22 \\
\hline Pax1 & NM 008780 & paired box gene 1 [Source M arkerSym bo lAcc M G I97485] & 5.18 \\
\hline Spt2 & NM 009268 & salinary prote in 2 [Source M arkerSym bo lA cc M G I98393] & 4.57 \\
\hline GG KV 4-57-1 & XM_357683 & m m unog bbu lin Kappa light chain V gene segm ent [Source:M G T/GENE-DB Acc:GGV 4-57-1] & 4.39 \\
\hline Ubash3a & NM 177823 & ub iquitin assoc iated and SH3 dom an containing, A [Source M arkerSym bo lA cc M G I:1926074] & 4.20 \\
\hline- & NM_010743 & - & 4.18 \\
\hline Rhox4e & NM 201236 & reproductive hom eobox 4E [Source M arkerSym bo lAcc M G I3613390] & 4.10 \\
\hline P la2g2a & NM 011108 & phospho lipase A2, group IIA (p late lets, synovial flu id) [Source M arkerSym bo l'Acc M G I:104642] & 4.02 \\
\hline B ank1 & XM_143587 & B-ce ll scaffo ld prote in w ith ankyrin repeats 1 [Source M arkerSym bo lA cc M G I2442120] & 3.88 \\
\hline Gp9 & NM 018762 & glycoprote in 9 (p late let) [Source M arkerS ym bo lAcc M G I:1860137] & 3.85 \\
\hline- & NM 016956 & - & 3.81 \\
\hline V snll & NM 012038 & vis in n-lke 1 [Source M arkerSym bo l'A cc M G I:1349453] & 3.80 \\
\hline P p5k1c & NM_008844 & phosphatidy linos ito-4-phosphate 5-knase, type 1 gam m a [Source M arkerSym bo IA cc M G I:1298224] & 3.80 \\
\hline 0 ffr329 & - & o lfactory receptor 329 [Source M arkerSym bolA cc M G I3030163] & 3.73 \\
\hline M yh3 & XM_354614 & m yosin, heavy po lypeptide 3, ske letalm usc le, em bryon ic [Source M arkerSym bo lA cc M G I:1339709] & 3.66 \\
\hline Nepn & NM 025684 & nephrocan [Source M arkerSym bo lAcc M G I:1913900] & 3.62 \\
\hline Nox1 & NM 172203 & NADPH oxidase 1 [Source M arkerSym bo l'Acc M G I2450016] & 3.62 \\
\hline 0 ffr921 & NM 146782 & o lfactory receptor 921 [Source M arkerSym bo l'Acc M G I3030755] & 3.61 \\
\hline- & NM 024204 & - & 3.57 \\
\hline Zfp142 & - & zinc finger prote in 142 [Source M arkerSym bo lAcc M G I:1924514] & 3.55 \\
\hline EG 225416 & XM_140295 & - & 3.53 \\
\hline Kont1 & - & potassium channe l, subfam ily T, m em ber 1 [Source M arkerSym bo |A cc M G I:1924627] & 3.52 \\
\hline Q 8C 3БM OUSE & - & 16 days neonate heart cDNA, R KEN fult- ength enriched lbrary, c bne D 830014A 20 product & 3.45 \\
\hline- & NM 133245 & - & 3.42 \\
\hline Gpr115 & - & G prote $\mathrm{n}$-coup led receptor 115 [Source M arkerS ym bolAcc M G I1925499] & 3.41 \\
\hline Q9QUL5M OUSE & NM 010416 & Hem T-3 prote in. [Source Un prot/SPTREM BL Acc Q 9QUL5] & 3.41 \\
\hline A tp1b2 & NM 013415 & A TPase, $\mathrm{Na}$ a $/ \mathrm{K}+$ transporting, beta 2 po lypeptide [Source $\mathrm{M}$ arkerSym bo lA cc M G I88109] & 3.38 \\
\hline $\mathrm{Hbb}-\mathrm{y}$ & NM_008221 & hem og bb in Y, beta- lke em bryonic chain [Source $M$ arkerSym bo lA cc M G I96027] & 3.37 \\
\hline 0 lfr963 & - & o lfactory receptor 963 [Source M arkerSym bo lA cc M G I3030797] & 3.35 \\
\hline 0 lfr958 & NM 146330 & o lfactory receptor 958 [Source M arkerSym bolAcc M G I3030792] & 3.34 \\
\hline X kd1 Lyve-1) & NM 053247 & extra ce lu lar link dom a in-containing 1 [Source M arkerSym bo l'A cc M G I2136348] & 3.32 \\
\hline Steap4 & NM 054098 & STEAP fam ily m em ber 4 [Source M arkerSym bo lAcc M G I:1923560] & 3.31 \\
\hline M yog & NM_031189 & m yogen in [Source $M$ arkerSym bol'A cc M G I97276] & 3.29 \\
\hline 0 lfr301 & NM 212436 & o lfactory receptor 301 [Source M arkerSym bo lA cc M G [3030135] & 3.29 \\
\hline Zdhhc20 & - & zinc finger, DHHC dom ain containing 20 [Source M arkerSym bo lA cc M G I:1923215] & 3.28 \\
\hline 0 lfr303 & NM 146619 & o lfactory receptor 303 [Source M arkerSym bo lA cc M G I3030137] & 3.28 \\
\hline Rhox4b & NM 021300 & reproductive hom eobox 4B [Source M arkerSym bo |Acc M G I:1930129] & 3.24 \\
\hline- & NM 175462 & - & 3.23 \\
\hline Hba-a1 & NM 008218 & hem og bb in a bha, adult chain 1 [Source M arkerSym bo l'A cc M G I96015] & 3.21 \\
\hline C lec1b & NM 019985 & C-type lectin dom an fam ily $1, \mathrm{~m}$ em ber b [Source M arkerSym bo lAcc M G I:1913287] & 3.19 \\
\hline- & NM 145435 & - & 3.15 \\
\hline S lc22a8 & NM 031194 & so lute carrier fam ily 22 (organic an ion transporter), m em ber 8 [Source M arkerSym bol'Acc M G I:1336187] & 3.12 \\
\hline Tnfsg5 & - & TNF-stim u lated gene 5 [Source M arkerSym bo l'Acc M G I3608660] & 3.11 \\
\hline 4833405L 16R k & NM 177197 & R KEN cDNA 4833405L16 gene [Source M arkerS ym bo lA cc M G I2444315] & 3.08 \\
\hline 0 ffr993 & NM 146435 & o lfactory receptor 993 [Source M arkerSym bo lA cc M G I3030827] & 3.01 \\
\hline Lrfn2 & XM_128642 & leuc ne rich repeat and fbronectin type III dom a in containing 2 [Source M arkerSym bo lA cc M G I:1917780] & 3.01 \\
\hline- & NM 146565 & o ffactory receptor 837 (0 Ifr837), m RNA [Source RefSeq_dnaAcc NM_146565] & 3.00 \\
\hline
\end{tabular}




\section{Supplemental Table 2. Genes downregulated in EBs treated with AM and SB431542 (<three fold)}

\begin{tabular}{|c|c|c|c|}
\hline Gene & $\begin{array}{l}\text { NCBI } \\
\text { Ref.Seq. }\end{array}$ & Description & $\begin{array}{l}\text { fold } \\
\text { change }\end{array}$ \\
\hline Lefty2 & NM_177099 & Left-right determ nation factor 2 [Source M arkerSym bo l'A cc M G I.2443573] & 0.05 \\
\hline Pga5 & NM__21453 & peps nogen 5, group I [Source M arkerSym bo lA cc M G I:1915935] & 0.08 \\
\hline M esp1 & NM__008588 & m esoderm posterior 1 [Source M arkerS ym bo l'A cc M G I:107785] & 0.12 \\
\hline NP_444473.1 & NM_ 053243 & protease, serine, 1 [Source RefSeq_peptide Acc NP_444473] & 0.14 \\
\hline Apoc2 & NM__009695 & apo lipoprote in C-II [Source M arkerSym bo lA cc M G I88054] & 0.15 \\
\hline Lhx1 & NM__008498 & L M hom eobox prote in 1 [Source M arkerSym bo lAcc M G I99783] & 0.15 \\
\hline Lefty1 & NM__10094 & left right determ ination factor 1 [Source M arkerSym bo l'A cc M G I:107405] & 0.18 \\
\hline M egf10 & NM_001001979 & m ultiple EGF-lke-dom a ins 10 [Source M arkerSym bo lAAcc M G I2685177] & 0.20 \\
\hline Irs4 & - & insulin receptor substrate 4 [Source M arkerSym bo l'A cc M G I:1338009] & 0.21 \\
\hline Apoa2 & NM 013474 & apo lipoprote in A-II [Source M arkerS ym bo lA cc M G I88050] & 0.21 \\
\hline M ixll & NM 013729 & M ix1 hom eobox-lke 1 (Xenopus laevis) [Source $M$ arkerSym bo lA cc M G I:1351322] & 0.22 \\
\hline Cyp26a1 & NM_007811 & cytochrom e P 450, fam ily 26, subfam ily a, po lypeptide 1 [Source M arkerSym bo l'A cc M G I:1096359] & 0.22 \\
\hline- & NM_134249 & - & 0.22 \\
\hline Angpt7 & - & ang iopo ietin-lke 7 [Source M arkerS ym bo l'A cc M G I3605801] & 0.23 \\
\hline Fgg & NM_133862 & fbrinogen, gam m a polypeptide [Source M arkerS ym bol'Acc M G I95526] & 0.23 \\
\hline A poa4 & NM_007468 & apo lipoprote in A-N [Source M arkerSym bo lA cc M G I88051] & 0.24 \\
\hline Trh & NM__009426 & thyrotrop in re leasing hom one [Source $M$ arkerS ym bo lAcc M G I98823] & 0.26 \\
\hline $\mathrm{T}$ & NM_009309 & brachyury [Source M arkerSym bo lA cc M G I98472] & 0.28 \\
\hline Prss35 & NM_178738 & protease, serne, 35 [Source M arkerSym bo lAcc M G I2444800] & 0.28 \\
\hline- & XM 127824 & - & 0.28 \\
\hline Bcll1b & NM 021399 & B-cell leukem ia/ lym phom a 11B [Source M arkerS ym bo lA cc M G I:1929913] & 0.29 \\
\hline Ccl17 & NM 011332 & chem okine (C $-C$ m otif) ligand 17 [Source M arkerS ym bo liAcc M G I:1329039] & 0.30 \\
\hline Tm epai & - & transm em brane, prostate androgen induced RNA [Source M arkerSym bo l'A cc M G I:1929600] & 0.30 \\
\hline Ptchd1 & XM_142262 & patched dom an containing 1 [Source M arkerSym bo l'A cc M G I2685233] & 0.31 \\
\hline Z ic5 & NM__22987 & zinc finger prote $n$ of the cerebe llum 5 [Source M arkerSym bo lA cc M G I:1929518] & 0.31 \\
\hline Igfbp1 & NM_008341 & insulin-lke grow th factor bind ing prote in 1 [Source M arkerSym bo lA cc M G I96436] & 0.32 \\
\hline Afp & NM_007423 & a pha fetoprote in [Source M arkerSym bo lAcc M G I87951] & 0.32 \\
\hline $1810049 \mathrm{H} 19 \mathrm{R} \mathrm{k}$ & NM_001003405 & R KEN cDNA $1810049 \mathrm{H} 19$ gene [Source M arkerSym bolA cc M G I3045752] & 0.32 \\
\hline $\mathrm{Fg} f 5$ & NM 010203 & fbrob last grow th factor 5 [Source M arkerSym bo l'Acc M G I95519] & 0.32 \\
\hline
\end{tabular}




\section{Supplemental Table 3. \\ Specific endothelial markers, early mesodermal markers and angiogenic factors in EBs treated with AM and SB431542}

$\begin{array}{lll}\text { Gene } & \text { NCBI } & \text { fold } \\ \text { change }\end{array}$

